\title{
Informative Trading or Just Noise? An Analysis of Currency Returns, Market Liquidity, and Transaction Costs in Proximity of Central Bank Interventions
}

\author{
Paolo Pasquariello ${ }^{1}$ \\ Stern School of Business - New York University
}

October 9, 2002

\footnotetext{
${ }^{1}$ Please address comments to the author at the Department of Finance, Leonard N. Stern School of Business, New York University, Kaufman Management Education Center, Suite 9-180, 44 West 4th Street, New York, NY 10012-1126, or via email: ppasquar@stern.nyu.edu. I am grateful to Andreas Fischer and Mathias Zurlinden, of the Swiss National Bank, for making available their database of interventions, and to Olsen \& Associates for having provided the tick-by-tick data on the Swiss Franc. I benefited from the encouragements and suggestions of Joel Hasbrouck and Marti Subrahmanyam, and from the comments of Menachem Brenner, Craig Holden, Jerry Kallberg, Arun Muralidhar, Lasse Pedersen, Angelo Ranaldo, and other participants at the 2001 DRP-Stern Research Retreat, the 2002 WFA Meeting, and the 2002 EFMA Meeting. Any remaining errors are my own.
} 


\begin{abstract}
We study the impact of Central Bank intervention on the process of price formation in currency markets. We use a unique dataset of tick-by-tick indicative quotes posted by dealers on Reuters terminals and of intraday sterilized spot interventions and customer transactions executed on behalf of the Swiss National Bank (SNB) on the Swiss Franc/U.S. Dollar exchange rate (CHFUSD) between 1986 and 1998. We find that potentially informative SNB interventions (but not ex post uninformative customer transactions), although small relative to daily trading volumes in the CHFUSD market, had significant and persistent (albeit asymmetric, depending on their sign) effects on daily currency returns, especially when (relatively) large in magnitude, expected by the market, or inconsistent with existing momentum. The market did not anticipate the occurrence of incoming interventions unless if chasing the trend. The SNB was much less successful in smoothing fluctuations of the currency, for daily CHFUSD volatility always surged in proximity of interventions, as did average absolute and proportional spreads. Decomposition of estimated absolute spread shocks also reveals that SNB actions induced misinformation among market participants, impacted trading immediacy, and increased market liquidity and competition among dealers. Many of these changes translated into higher transaction costs borne by the population of investors.
\end{abstract}

JEL classification: E58; F31; G15

Keywords: Sterilized Central Bank Intervention; Market Microstructure; Foreign Exchange; Information; Inventory 


\section{Introduction}

Central Bank interventions are one of the most interesting and puzzling features of the global foreign exchange (forex) markets. More often than usually believed, domestic monetary authorities engage in individual or coordinated efforts to influence exchange rate dynamics. The need to strengthen or resist an existing trend in a key currency rate, to calm disorderly market conditions, to signal current or future stances of economic policy, or to replenish previously depleted foreign exchange reserve holdings are among the most frequently mentioned reasons for this kind of operations.

There is strong consensus in the economic literature (e.g., Adams and Henderson (1983)) that unsterilized interventions, by affecting the existing stock of high-powered money, influence the exchange rate through the traditional channels of monetary policy. The effectiveness and necessity of sterilized interventions, i.e., accompanied by offsetting actions on the domestic monetary base, is instead still controversial, and, as such, at the center of the current theoretical and empirical debate. ${ }^{1}$

Within the macroeconomic approach, sterilized intervention may affect the exchange rate through either of two channels, imperfect substitutability and signaling. The first channel is usually examined in the context of portfolio balance models of exchange rate determination (e.g., Branson (1983, 1984)), in which market participants, being risk-averse, need to be compensated for holding positions they would have not otherwise kept in their portfolios, had the intervention not occurred. The second channel of influence (Mussa (1981), Bhattacharya and Weller (1997)) allows sterilized intervention to affect quotes and transaction prices by conveying not only information on policy intentions but also fundamental information about the future value of the currency. ${ }^{2}$

Regardless of their effectiveness, the presence of active price manipulators in the otherwise very liquid and (widely recognized as) efficient forex markets also raises another question of common interest to analysts, researchers, and policy-makers. How do transactions executed on behalf of the Central Bank

\footnotetext{
${ }^{1}$ For example, many authors (e.g., Taylor (1982)) emphasize how costly these operations are, especially with respect to their immediate, albeit rarely long-lasting, desired effects. The survey article by Sarno and Taylor (2001) offers a detailed account of this debate.

${ }^{2}$ Much of the existing empirical literature on imperfect substitutability (see Edison (1993) for a review) finds that portfolio balance effects of official interventions on the exchange rate are only small and short-lived. More recently however, Evans and Lyons (2001) show that even sterilized, secret, and uninformative Central Bank interventions may have an impact on the exchange rate if they generate interdealer order flow. Stronger supporting evidence is available for the signaling channel, e.g., Dominguez (1987) and Kaminsky and Lewis (1996).
} 
affect the process of price formation in the currency market and, in particular, not just exchange rate returns but return volatility, the market's ability to process information, and investors' ability to trade? Many recent market microstructure studies focus on each of these issues separately, and suggest that such transactions might significantly affect exchange rate returns, market volatility, or liquidity. ${ }^{3}$ However, the available empirical evidence, often based on currency data collected just on daily basis (hence, not necessarily representative of the dynamics of market quotes, spreads, and daily variability), and in many cases just on second-hand information about the timing, direction, or size of official interventions, offers only mixed support for these claims. The same evidence also does not appear to be sufficient to assess the relative importance of inventory versus risk-aversion versus information asymmetry considerations in explaining the estimated effects of the actions of a Central Bank on the process of price formation in the forex markets.

In this study, we explore all these research questions in a comprehensive manner. Indeed, the novelty of this paper is in considering a broader perspective in which we ask not only whether interventions are eventually effective but also whether they impact exchange rate volatility, market liquidity, and transaction costs in a significant way independently of their effectiveness, and how those effects interact with each other in proximity of their occurrence. To that purpose, we investigate all sterilized spot interventions and customer transactions executed by the Swiss National Bank (SNB), the Swiss Central Bank, on the Swiss Franc/U.S. Dollar exchange rate (CHFUSD) between January 2, 1986 and December 31, 1998. The CHFUSD is among the most liquid currency pairs traded in the global forex markets, and the SNB is one of the most active and credible monetary authorities in the financial world.

Although official interventions may be informative about economic fundamentals and policy intentions, customer transactions are not, as they are instead conducted for reasons other than exchange rate management. Hence, we utilize them as a control sample to evaluate the relevance of information and inventory-based theories of the impact of Central Bank interventions on currency returns, return volatility, and transaction costs. We then build a database matching SNB actions with tick-by-tick quotes posted by dealers on Reuters terminals and recorded by Olsen \& Associates. Albeit purely indicative, those bid and ask prices are often utilized in the literature to proxy for the dynamics of (generally unavailable) transaction rates and effective spreads on over-the-counter forex markets like the one for the CHFUSD. We

\footnotetext{
${ }^{3}$ An albeit incomplete list of such papers includes Kaminsky and Lewis (1996), Dominguez (1998, 1999), Fischer and Zurlinden (1999), Naranjo and Nimalendran (2000), Evans and Lyons (2001), Pasquariello (2001a), and Payne and Vitale (2001).
} 
use these intraday quotes to compute daily measures of exchange rate behavior, ex post volatility, market liquidity, and trading intensity. We work with daily aggregations to investigate the lower-frequency impact of intraday SNB trades on any such variable, hence to bridge both the macro and microstructure literatures on Central Bank intervention, along the lines of Evans and Lyons (2002).

When we analyze these transactions with event-study methodology, we find that official SNB interventions, despite accounting for only a small portion of the average daily turnover in the CHFUSD market, significantly affected each of the variables of interest in both the short- and the long-term. Official interventions have persistent effects on currency returns, lasting for several days after being executed, especially when (relatively) large in magnitude, expected by the market, or inconsistent with existing momentum. The market did not anticipate the occurrence of incoming interventions unless if chasing the trend. The Swiss monetary authority was much less successful in calming disorderly market conditions by reducing exchange rate variability. Ex post measures of currency volatility in fact always surged in proximity of its interventions and stayed high for many days afterwards. Absolute and proportional spreads for the CHFUSD were also affected prior to SNB official transactions. For example, we estimate that (annualized) transaction costs borne by investors and speculators increased by around $\$ 100$ to over $\$ 400$ million in days when the SNB was selling USD, while they decreased on average by $\$ 150$ to $\$ 640$ million when the Swiss monetary authority was engaged in USD purchases. Changes would be of even greater magnitude if computed on a cumulative basis over wider event windows. Many of these effects were found to be statistically or economically negligible when (ex post uninformative) customer transactions were examined, suggesting that the potential information content of SNB interventions must have played an important role in explaining their impact on the CHFUSD market.

To further explore these issues, we extend the model of Fedenia and Grammatikos (1992) to decompose daily shocks in transaction costs at or around the time of SNB trades into shocks related to misinformation, liquidity, fundamental volatility, competition, and immediacy. This analysis reveals that official interventions (especially if big in size or expected by the market) induced greater heterogeneity of beliefs among market participants, impacted significantly trading immediacy and ex post exchange rate variation (except if chasing the trend), and increased market liquidity and competition among dealers for the incoming orders. Many of these changes were costly, i.e., translated into higher transaction costs borne by the population of investors, even when the interventions were not effective in reversing the existing market momentum or in smoothing fluctuations of the exchange rate. 
The paper is organized as follows. Section 2 describes our unique dataset and its basic features. In Section 3 a detailed analysis of the behavior of currency returns, return volatility, and market liquidity is performed using event-study methodology. Specification of a model to identify sources of shocks to absolute and proportional spreads in proximity of Central Bank trades and its estimation for SNB activity are in Section 4. In Section 5 we consider the issue of whether the magnitude of the intervention, its sign with respect to existing market momentum, or the degree of surprise accompanying it are relevant in explaining some of the main findings of this study. Finally, in Section 6 we summarize our results and outline potential extensions of our work.

\section{Data}

In this study we use two basic datasets. The first contains transactions conducted by the SNB on the CHFUSD exchange rate between 1986 and 1998. The second includes tick-by-tick indicative bid and ask quotes on CHFUSD posted on the FXFX Reuters screen over the same sample period. In the next two subsections, a more accurate description of the available data is provided, and their main features and properties are investigated.

\subsection{Central Bank transactions}

Most of the existing empirical research on the impact of interventions on quotes and spreads utilizes exclusively daily or weekly amounts of domestic currency negotiated in secret (hence unbeknownst to many market participants) by the corresponding Central Bank. Further information on these transactions, e.g., time of execution or settlement price, is also generally unavailable. Therefore, to control for any discrepancy between actual and reported interventions and to shed more light on the effects of such actions in the forex markets, some authors attempt to construct time series of interventions using the history of newswire reports generated by information networks like Reuters, as in the case of Dominguez (1999). However, as pointed out by Osterberg and Wetmore Humes (1995), among others, media reports on interventions are often less than accurate. Hence, the resulting series of events may depend crucially on the selected sources and on the criteria adopted to filter the relevant news. In order to study the impact of interventions on the daily process of price formation in the currency markets, this paper uses a collection of all intraday spot, ex post heralded transactions conducted by the SNB on CHFUSD between 1986 and 1998. A detailed description and 
preliminary analysis of this dataset can be found in Fischer and Zurlinden (1999). Trades executed on behalf of the SNB in the spot forex markets can be of two types, interventions and customer transactions.

It is rather infrequent, according to the available evidence, that a domestic monetary authority would not sterilize its actions in the forex market with offsetting open market trades to preserve its previous stance of monetary policy. As mentioned earlier, current empirical and theoretical work on Central Bank intervention concentrates mainly on sterilized currency transactions, and on the puzzling issue of why they appear to be often effective, at least in the short term. We focus our attention on sterilized interventions in this research as well. The Swiss Central Bank resumed its attempts at managing the fluctuations of the CHF in November 1986, after a three-year break, and ended them in December 1995. The SNB did not intervene between 1996 and 1998. According to Fischer and Zurlinden (1999, p. 664), the SNB intervened principally "to affect the trend of the exchange rate or to counteract market disturbances," although in some instances solidarity with other Central Banks may have represented an important motive as well. Not surprisingly indeed, most of the SNB interventions in the dataset were not only sterilized and ex ante unannounced but also coordinated, i.e., in most cases the Bundesbank and/or the Federal Reserve intervened on the same day and in the same direction as the SNB. There were only three days when the SNB acted alone in the CHFUSD market, and in such circumstances it did not neutralize in full the effect of its actions on domestic liquidity. We therefore remove those days from the sample. ${ }^{4}$

Customer transactions are purchases and sales of USD triggered by the Swiss government's requests for foreign and domestic currency. For example, when the government needs U.S. Dollars, the SNB supplies it with the desired amount by reducing its USD holdings. This leads to a steady outflow of dollars from the SNB's reserves. Thus, the SNB defines customer transactions as all transactions conducted in order to replenish (usually not immediately, but only after some time) its foreign exchange reserve holdings depleted by the actions of the true customer (the government), i.e., more generally as all transactions motivated by reasons other than exchange rate management.

Immediately after its transaction is concluded, the SNB informs the counterparty of the nature of the trade, i.e., whether the sale or the purchase of CHF represents an intervention. Fischer and Zurlinden observe that the intervention announcement spreads rapidly across the market and is eventually picked up by news agencies and mentioned in their newswire reports. It is

\footnotetext{
${ }^{4}$ The dates when unsterilized SNB interventions occurred are December 27, 1989 and March 6 and 11, 1992.
} 
then reasonable to assume that dealers experience no difficulties in identifying the SNB as a counterparty and, together with all other market participants, in distinguishing interventions from customer transactions after they have been executed. It is also reasonable to assume that customer transactions should be considered ex post uninformative.

For each transaction, the SNB reports the amounts traded, the negotiated price, and the (Zurich) time of occurrence, rounded to the nearest minute. The time stamp corresponds to when the trade slip was filled out, i.e., immediately after the deal is concluded. All available data refer to a single transaction executed at the given time by the SNB with a single dealer. Negotiated prices are based on market exchange rates, for the SNB does not act as a market-maker. SNB does most of its forex transactions with local banks, including local branches of foreign intermediaries, i.e., in Zurich but not in London or New York. ${ }^{5}$ Each dealer/counterparty does not know the total amount of the intervention/customer transaction (if it is composed of several transactions with more traders on the same day).

In Table 1 we report descriptive statistics on intraday SNB interventions, $I_{t_{\mathrm{i}}}$, and customer transactions, $C_{t_{\mathrm{i}}}$, where $i$ is the $i$-th trade on day $t$ and transacted amounts are in millions of U.S. Dollars. In Table 2 we aggregate and summarize the SNB activity on a daily basis. The SNB intervened 709 times over 102 days, and executed 555 customer transactions over 326 days. ${ }^{6}$ Although SNB-originated trades went in both directions, about two-thirds of the interventions were dollar sales, while most of the customer transactions are made of dollar purchases, as expected. Consequently, mean and median intervention (customer transaction) size are negative (positive) at the intraday and daily level. In addition, the quantities $I_{t_{\mathrm{i}}}$ and $C_{t_{\mathrm{i}}}$ are negatively and positively skewed, respectively, but are both leptokurtic. Positive and negative intraday interventions and customer transactions have the same median size ( $\$ 10$ million). However, $I_{t_{\mathrm{i}}}<0$ and $C_{t_{\mathrm{i}}}>0$ are more dispersed in magnitude. Daily aggregated interventions $\left(I_{t}\right)$ are greater on average than customer transactions $\left(C_{t}\right)$ of the same sign, but both represent only a very small fraction of the mean daily turnover in the CHFUSD market (around $\$ 80$ billion, as estimated by the Bank for International Settlements (BIS, 1999)). ${ }^{7}$ Customer transactions seem to be less concentrated on particular

\footnotetext{
${ }^{5}$ In few cases, in 1997 and 1998, the SNB executed some customer transactions (for a total of $2.34 \%$ of the sample) via the Electronic Brokerage System (EBS) in London.

${ }^{6}$ We discard three days, June 27, 1986, July 24, 1986, and January 19, 1987, in which the Swiss Central Bank bought dollars to replenish its reserves of hard currency, but for which we have no corresponding tick-by-tick indicative quotes on the CHFUSD.

${ }^{7}$ The BIS (1999) triennial survey of currency market activity for 1998 reports that about $\$ 1.5$ trillion in transactions are executed in the global forex market every day, of
} 
days. There instead appears to be some clustering of intervention events on Fridays. Interventions also typically hit a greater number of dealers, although with much smaller mean intraday volumes. Indeed, the average number of interventions per day is significantly higher than the corresponding number of customer transactions (6.95 versus 1.70). This suggests that the SNB attempted to achieve the maximum visibility for its intervention actions either by splitting the planned daily amounts over more intraday trades or by executing more transactions during the same day.

Figure 1 offers a glimpse of the intraday patterns of SNB actions emerging from the sample. The graph displays the number of interventions and customer transactions over fifteen minute-intervals from 5 a.m. to 4 p.m. Greenwich Mean Time (GMT). Most of the interventions appear to occur between 6 and 10 a.m. or between 12:30 and 3 p.m. GMT. The number of $I_{t_{\mathrm{i}}}$ peaks in the Zurich afternoon (around 1 p.m. GMT) at the opening of the New York market, that is when coordinated intervention with the Federal Reserve is more likely to take place. Customer transactions are characterized by a similar pattern, but are more frequent during the Zurich morning. ${ }^{8}$

\subsection{CHFUSD quotes}

The foreign exchange market is probably the most active financial market in the world, in terms of volume, frequency, and intensity of trading. Pasquariello (2001a) discusses in detail the main characteristics of the global currency markets and its differences with most equity and futures markets. Trading activity in exchange rates is decentralized and, as emphasized by Hsieh and Kleidon (1996), occurs 24 hours a day over three main regional markets: Tokyo, London, and New York. The closing hours of the Asian markets overlap with the opening of London, Frankfurt, and Zurich. The overlap is more substantial between European and American trading activity. The main players in the forex markets are dealers, brokers, and customers. Currency dealers are generally large and medium-sized commercial and investment banks, whose other business activities might also require extensive currency transactions. Those institutions operate as dealers, trading on their own accounts with each other as well as with non-bank customers, including institutional investors, hedge funds, big and small corporations,

which approximately $5 \%$ is explained by trading in the CHFUSD.

${ }^{8}$ In addition, Fischer and Zurlinden (1999) argue that the pattern exhibited by the SNB interventions in Figure 1 seems to mimic the intraday fluctuations in trading volume documented for example by Müller et al. (1990), thus suggesting that the Swiss monetary authority does not attempt to manage the fluctuations of the CHFUSD when trading is thin. 
and multinational firms. Brokers instead simply bring together dealers who wish to buy or sell the foreign currency. Dealers indicate their willingness to trade by posting quotes on electronic news systems provided by outside vendors like Reuters, Telerate, or Knight Ridder. However, those prices do not commit the dealer to execution. Dealers also quote on demand a bid or ask price for the currencies they deal with, and are required to transact at the proposed rates. Actual transactions are completed privately or through electronic communication, as in the Reuters 2000 Dealing System. Hence, information regarding transaction prices and volumes is proprietary and known exclusively to the parties involved in the transaction.

The raw exchange rate dataset used in this study consists of all continuously recorded quotes for CHFUSD appeared on the interbank Reuters FXFX screen between January 2, 1986 and December 31, 1998. These prices have been collected by Olsen \& Associates using in-house real-time data retrieval software. Each of the available quotes contains a bid price $\left(B_{t_{\mathrm{n}}}\right)$, an ask price $\left(A_{t_{\mathrm{n}}}\right)$, and the (GMT) time when it first appeared on the Reuters terminals, rounded to the nearest second. Such quotes are irregularly spaced in time, simply indicative (i.e., non-binding), and plagued by many microstructure frictions (e.g., clustering of the posted bid-ask spreads and strategic quote positioning) which have been extensively studied in the literature. ${ }^{9}$ As suggested by Andersen et al. (2002), these frictions, although typically relevant over intraday intervals, become immaterial when analyzing longer-horizon aggregates. In this study, we intend to evaluate the impact of SNB interventions and customer transactions on the process of price formation in the CHFUSD market. To accomplish this task, while controlling for the distortions that those microstructure features of the data may induce to the statistical analysis, we therefore choose to focus our investigation on daily measures of exchange rate behavior, ex post volatility, market liquidity, and trading intensity constructed using the available intraday quotes.

The data are first filtered to eliminate extreme outliers and rates at which it was extremely unlikely that a transaction would have occurred, using the procedure recommended by Dacorogna et al. (1993). Along the lines of Bollerslev and Domowitz (1993) and Andersen and Bollerslev (1997), we also remove all prices recorded during weekends and during the Asian daylight hours (9 p.m. to 5 a.m. GMT) from the dataset, as trading activity over

\footnotetext{
${ }^{9}$ See, for example, Bessembinder (1994) and Hasbrouck (1999) for an analysis of clustering in indicative quotes on DEMUSD. Bollerslev and Melvin (1994) suggest that reputation effects may prevent the posting of quotes at which a bank would not subsequently be willing to trade. Goodhart et al. (1996) and Dominguez (1999) compare those quotes with short sample of spot transactions and find that intraday indicative spreads overestimate the magnitude of transacted spreads and the relevance of clustering.
} 
those periods is significantly slower, and many fewer quotes are posted on the FXFX page. In the end, we eliminate about $11 \%$ of the original observations, but still remain with slightly less than 6.3 million validated intraday quotes.

As in Müller et al. (1990) and Andersen and Bollerslev (1997), we define the $n$-th tick-by-tick midquote return for day $t, r_{t_{n}}$, as the difference between the midpoint of the logarithmic bid and ask at the $n$-th and $(n-1)$-th quotes on day $t$,

$$
r_{t_{\mathrm{n}}}=\frac{1}{2}\left[\ln \left(B_{t_{\mathrm{n}}}\right)+\ln \left(A_{t_{\mathrm{n}}}\right)\right]-\frac{1}{2} \stackrel{\mathbf{f}}{\ln } \mathbf{i}^{\mathbf{i}} B_{t_{\mathrm{n}-1}}{ }^{\dagger}+\ln ^{\mathbf{i}} A_{t_{\mathrm{n}-1}} \mathbf{\phi}
$$

This definition of midquote return has the advantage of being symmetric with respect to the denomination of the exchange rate, that is with respect to whether we focus on CHFUSD or on USDCHF. However, the return numbers generated from Eq. (1) are only negligibly different from the usual logreturns ensuing from the more conventional midquote $\frac{1}{2}\left(B_{t_{\mathrm{n}}}+A_{t_{\mathrm{n}}}\right)$. We then specify the tick-by-tick bid-ask spread on an absolute and relative basis as $S_{t_{\mathrm{n}}}=\left(A_{t_{\mathrm{n}}}-B_{t_{\mathrm{n}}}\right) \times 10,000$ (i.e., in units of basis points) and, consistent with Eq. (1), $s_{t_{\mathrm{n}}}=\ln \left(A_{t_{\mathrm{n}}}\right)-\ln \left(B_{t_{\mathrm{n}}}\right)$, respectively. In particular, the variable $s_{t_{\mathrm{n}}}$, the logarithmic spread of the last valid price before $t_{n}$, again suggested by Müller et al. (1990), is a good proxy for the proportional spread. We also compute tick-by-tick absolute returns, $\left|r_{t_{n}}\right|$, tick-by-tick duration $d_{t_{n}}$ as the length of time (in seconds) between consecutive quotes, and the frequency variable $f_{t}$ as the number of posted quotes over day $t$ of the sample.

Finally, we define the cumulative return and absolute return over day $t, r_{t}$ and $\left|r_{t}\right|$, as the cumulated sum of the tick-by-tick returns computed according to Eq. (1), i.e., $r_{t}={ }_{n=1}^{\mathrm{Pt}} r_{t_{\mathrm{n}}}$ and $\left|r_{t}\right|={ }_{n=1}^{\mathrm{Pt}}\left|r_{t_{n}}\right|$, respectively. The daily absolute return $\left|r_{t}\right|$ is a first proxy not only for market volatility, as in Payne and Vitale (2001), but also for the intensity of informational events and information shocks, as suggested by Chordia et al. (2000). We also define an additional proxy for daily realized exchange rate volatility, the square return measure $r_{t}^{2}$, by computing the cumulated sum of all intraday square returns $r_{t_{n}}^{2}$, that is $r_{t}^{2}={ }_{n=1}^{\mathrm{Pt}} r_{t_{\mathrm{n}}}^{2}$. Andersen et al. (2002) show that, under suitable conditions, the ex post realized quadratic variation at time $t, r_{t}^{2}$, representing the realized sample path variation of the square return process $r_{t_{n}}^{2}$, is an unbiased estimator of daily return volatility conditional on information at time $t-1$ which is asymptotically free of measurement error. Finally, we define $S_{t}, s_{t}$, and $d_{t}$ as the arithmetic means of their corresponding tick-by-tick series of absolute spread $S_{t_{\mathrm{n}}}$, logarithmic spread $s_{t_{\mathrm{n}}}$, and duration $d_{t_{\mathrm{n}}}$ over day $t$. 
Table 3 collects some basic descriptive statistics for each of those variables over 3,352 trading days. The cumulated daily CHFUSD return $r_{t}$ is characterized by a mean of zero, little or no skewness, and strong and significant leptokurtosis. The first-order estimated autocorrelation $\left(\mathbf{b}_{1}\right)$ is small and statistically indistinguishable from zero, but the computed value for the Ljung-Box portmanteau test for up to the fifth-order serial correlation, $L B(5)$, rejects the null hypothesis that returns are white noise. Both the proxies for return volatility $\left(\left|r_{t}\right|\right.$ and $\left.r_{t}^{2}\right)$ and the frequency of arrivals of new quotes $\left(f_{t}\right)$ show instead strong positive linear dependence. On average, almost 1,900 new quotes are posted every day by dealers on the FXFX page of the Reuters terminals. Figure 2, which plots the mean daily frequency $f_{t}$ over each of the years in the sample, reveals an increasing trend in this variable. This renewed interest in the CHFUSD occurs in correspondence with the process of convergence of most EU currencies approaching the deadline for the Monetary Union, and the resulting increasing correlation among them. The average duration between consecutive new indicative quotes $\left(d_{t}\right)$ is roughly one minute. The corresponding estimated skewness and kurtosis are very large, and do not seem to be compatible with a Gaussian distribution. The mean absolute spread is about 9.43 basis points. The mean proportional bid-ask spread is small, around $0.066 \%$, with respect to the values usually observed in most equity markets, an additional point in support of the often mentioned high liquidity of the global exchange rate markets. The parameter $\mathrm{p}_{1}$ and the statistic $L B(5)$ are positive and statistically significant for both $S_{t}$ and $s_{t}$.

The evidence of positive autocorrelation for most of the variables in the sample suggests the presence of weekday cycles of activity in the CHFUSD market. To explore this possibility, Figure 3 displays means of daily values for $r_{t},\left|r_{t}\right|, r_{t}^{2}, S_{t}, s_{t}$, and $f_{t}$, and the corresponding $95 \%$ confidence intervals, computed over different days of the week. Average cumulated returns $r_{t}$ (Figure 3a) are never significantly different from zero unless on Thursdays. All other variables instead show meaningful weekday patterns. In particular, our proxies for exchange rate volatility, $\left|r_{t}\right|$ and $r_{t}^{2}$ (Figures $3 \mathrm{~b}$ and 3c), tend to be much higher by the end of the trading week, and so do absolute and logarithmic spreads (Figures 3d and 3e), while many more quotes appear to be posted by dealers on the FXFX page on Tuesdays and Wednesdays (Figure 3f).

Overall, and consistent with other studies on similar time series, the CHFUSD market features economically and statistically significant daily periodicity in the volatility of the traded asset, in market activity, and in the transaction costs that dealers charge to investors and banks as a compensation for providing their liquidity services. Market microstructure theory 
traditionally relates the seasonal dynamics of these variables to inventory control considerations, asymmetric information between dealers and profitmaximizing speculators, and order processing. ${ }^{10}$ Aware of these properties of the our dataset, in the next sections we investigate whether (and how) the actions of a particular type of trader, a Central Bank engaged in currency management, may affect not only currency returns but also exchange rate volatility and market liquidity.

\section{Seasonalities, long-term trends, and the es- timated impact of intervention}

In this section we analyze the effect, if any, of Central Bank-originated trades on the process of price formation in the CHFUSD market by merging the dataset of indicative quotes posted on the Reuters FXFX page from January 2, 1986 to December 31, 1998 with the collection of official interventions and customer transactions executed on behalf of the SNB over the same period of time. The resulting joint database contains tick-by-tick validated quotes, the daily variables $r_{t},\left|r_{t}\right|, r_{t}^{2}, S_{t}, s_{t}, f_{t}$, and $d_{t}$ (defined in Section 2.2), and the intraday and daily aggregated transactions involving the SNB (described in Section 2.1). There are 86 days in the sample when only official interventions $(I)$ were observed. In 18 of them the SNB purchased USD $(I>0)$, while selling it in the remaining $68(I<0)$. Customer transactions $(C)$ were more frequent. There are 310 days in which they occurred, of which 298 are characterized exclusively by dollar purchases $(C>0)$, and just 12 by dollar sales $(C<0)$. There are also 16 days in which the SNB bought dollars both for official intervention purposes and as pure customer transactions $(I \& C)$. Customer transactions are very important for this research because they are not supposed to be informative ex post, hence will be used as a control sample to verify the relevance of information considerations to any estimated effect of official interventions on the variables of interest.

To evaluate the economic and statistical significance of the impact of SNB trades on currency returns, market liquidity, and exchange rate volatility, two very important issues must be addressed. First, does any long-term trend in the absolute and logarithmic spread, absolute and square return, duration and frequency of the posted quotes affect the dynamics of those variables at or around the time when the SNB was executing official interventions or

\footnotetext{
${ }^{10} \mathrm{O}$ 'Hara (1995) provides a comprehensive review of the market microstructure literature dealing with issues associated with inventory and information economics, while the monograph of Lyons (2001) reinterprets and extends many of these issues in the context of forex markets.
} 
customer transactions? In our sample, none of the subcategories of SNB actions is concentrated over any particular day or during any particular month of the sample. Nonetheless, intervention events (but not customer transactions) happen more frequently on Tuesdays and Fridays, and especially before 1990, thus raising some concern about weekday and long-run cycles in SNB activity.

Most of the variables in our dataset are characterized by pronounced temporal trends as well. ${ }^{11}$ For example, in Figure 2 we showed that the mean daily number of posted quotes $f_{t}$ has been increasing over the last 10 years of the sample. So do both the realized volatility $r_{t}^{2}$ and cumulated absolute returns, while daily cumulated returns $r_{t}$ do not appear to display any discernible trend during the same time-frame. The average duration between consecutive new posted quotes instead drops from about 100 seconds in 1986 to less than 50 seconds in 1998. Although the mean proportional spread fluctuates swiftly over the sample period, average daily absolute spreads decline steadily from 1986 to 1996, albeit recovering somewhat in 1997 and 1998. Furthermore, the analysis of Section 2.2 revealed statistically robust weekday seasonalities for many of those variables. Clearly, these results show the need to control explicitly for short-term seasonalities and long-term trends in assessing the impact of Central Bank activity on the dynamics of the CHFUSD exchange rate.

Second, there is some empirical evidence, e.g., Payne and Vitale (2001), that market participants tend to anticipate official interventions. Additionally, most of the theoretical and empirical debate surrounding Central Bank intervention, the most recent example of which is Evans and Lyons (2001), is centered around the issue of establishing whether any of the effects of those actions are of permanent or of just temporary nature. It is thus of interest to determine whether exchange rate volatility increases or decreases prior to official interventions, how early currency dealers modify their posted quotes and spreads in response to expectations of future SNB actions, and finally how persistent these changes in CHFUSD returns, volatility, and market liquidity are in the days immediately following the SNB-originated transactions.

Both these sets of questions we tackle by specifying, for each daily aggregated variable of interest $X_{t}$ (from $r_{t}$ to $f_{t}$ ) and for the set of events of type $h$, the following two basic regressions:

$$
X_{t}=\alpha+{ }_{l=1}^{\mathrm{P} 2} \gamma_{l} X_{t-l}+\delta_{0} I_{t}(0, h)+{ }_{i=1}^{\mathrm{P}} \psi_{i} D_{t}(i)+{ }_{k=1986}^{1 \mathrm{P} 997} \vartheta_{k} Y_{t}(k)+\varepsilon_{t}
$$

\footnotetext{
${ }^{11}$ For economy of exposition, these trends are not reported here, but are available on request from the author.
} 
and

$$
X_{t}=\alpha+{ }_{l=1}^{\mathrm{P} 2} \gamma_{l} X_{t-l}+{ }_{j=-K}^{\mathrm{P}} \delta_{j} I_{t}(j, h)+{ }_{i=1}^{\mathrm{P}} \psi_{i} D_{t}(i)+\underbrace{\mathrm{P9}}_{k=1986} \vartheta_{k} Y_{t}(k)+\varepsilon_{t}
$$

where $h=I, I>0, I<0, C, C>0, C<0$, or $I \& C$, and $I_{t}(j, h)$ is an unsigned event dummy variable equal to 1 in day $t$ if during day $t+j$ the SNB was executing a transaction of type $h$, and equal to zero otherwise. The use of unsigned dummies allows us to explore the possibility of asymmetric impact of purchases and sale of USD by the SNB on any $X_{t}$. Nonetheless, in the special case in which $X_{t}=r_{t}$ and $h=I, C$, or $I \& C$, we substitute the regressor $I_{t}(j, h)$ with the signed event dummy $I_{t}^{*}(j, h)$ equal to $1(-1)$ if the SNB was executing a purchase (sale) of USD of type $h$ during day $t+j$, and equal to zero otherwise, to prevent the estimation of Eqs. (2) and (3) from averaging across effects of opposite sign. For $i=1$ (Monday), ..., 4 (Thursday), $D_{t}(i)$ is a day-of-the-week dummy, while $Y_{t}(k)$ is a year dummy, for $k=1986, \ldots, 1997$. Eqs. (2) and (3) also include lags of $X_{t}$ of order 1 and 2 to control for the autocorrelation in the dependent variables found in Table 3. In order to accommodate heteroskedasticity and serial correlation issues, we estimate those regressions using a standard GMM procedure and compute Newey-West standard errors.

How do we interpret the resulting coefficients' estimates? The coefficient for the contemporaneous indicator $I_{t}(0, h)$ (or $\left.I_{t}^{*}(0, h)\right), \delta_{0}$ in Eq. (2), is a proxy for the impact of the event of type $h$ on $X_{t}$ at time $t$, after accounting for weekday patterns and any long-term trend in the variable. The same coefficient $\delta_{0}$ for $j=0$ in Eq. (3) becomes a measure of the marginal revision of the cumulated impact of the signed action on $X_{t}$ up to (but not including) time $t$. If instead $j>0$, the coefficient on $I_{t}(j, h)$ (or $\left.I_{t}^{*}(j, h)\right), \delta_{j}$, is a measure of anticipation, i.e., of the marginal impact of the action of type $h$ on the variable at time $t$ before that action actually occurs at time $t+j$. Vice versa, if $j<0$, the coefficient $\delta_{j}$ is a measure of persistence, i.e., a measure of the marginal impact of the same action type $h$ on the variable at time $t$ after that action has already occurred at time $t+j$. Hence, successively cumulated sums $b_{-w}^{h}$ of the event-dummy coefficients of this regression can be interpreted as measures of the cumulated impact of the action $h$ under examination on the corresponding variable up to day $t-w$. Thus, if for example $h=I, X_{t}=S_{t}$, and $w>0(w<0)$, then $b_{-w}^{h}={ }_{j=w}^{\mathrm{PB}} \boldsymbol{B}_{j}$ is an estimate of the cumulated impact of official SNB interventions on the absolute spread up to $|w|$ days before (after) interventions of type $I$ occur. 


\subsection{Marginal impact of SNB actions}

We first report estimates of the coefficient $\delta_{0}$ in Eq. (2) for each of the variables of interest in Table 4 . The most striking result there displayed is that, after controlling for its short and long-term trends, exchange rate volatility, as measured both by the absolute return $\left|r_{t}\right|$ and the realized conditional variation $r_{t}^{2}$, increases following both official purchases and sales of USD on behalf of the SNB. Hence, interventions by the Swiss monetary authority on the CHFUSD appear to increase the dispersion of beliefs among market participants, regardless of their direction.

The impact on market volatility is highest in the fewer circumstances when the SNB was selling the domestic currency, the CHF. "Calming disorderly markets" and smoothing the fluctuations of the target exchange rate are however among the priorities of most Central Banks, but also clearly the tasks at which the SNB was the least successful. To support our assertions, in the control sample represented by ex post uninformative customer transactions, i.e., by trades that were not supposed to alter dealers and investors' expectations about fundamentals and policy objectives of the Central Bank, no statistically significant change in the proposed measures of market volatility is instead observed.

Cumulated returns in intervention days, free of weekday and yearly patterns, are consistent with the direction of the corresponding official intervention by the SNB. ${ }^{12}$ The CHF was on average weaker in days when the Swiss Central Bank was buying USD and stronger in days when dollars were sold. Nonetheless, these excess returns are not significantly different from zero at any conventional level. Not surprisingly, the coefficient $\boldsymbol{B}_{0}$ is negative and significant when $h=C>0$, thus suggesting that the SNB was purchasing dollars to replenish its reserves, or for what Pasquariello (2001b) calls wealth-preservation motives, in days when the CHF was strong.

As pointed out by Dominguez (1999), Central Banks rarely offer information regarding the motivations for their official interventions, specific goals, and target levels that the domestic currency is supposed to achieve, or the time-frame over which these goals should be met, and the SNB is no exception. Moreover, investors' and traders' perception of the objectives of those actions may affect their final effectiveness, regardless of the Central Bank's efforts. Thus, the task of evaluating the success of a monetary authority's

\footnotetext{
${ }^{12}$ To emphasize again the relevance of weekday cycles of activity and long-term trends in the CHFUSD market, most day-of-the-week and year dummy coefficients in both Eqs. (2) and (3) for each of the variables under examination were strongly significant, and the corresponding adjusted $R^{2}$ were large. Hence, these effects appear to capture a meaningful portion of the variation experienced by each of the variables we consider in this study.
} 
attempt at managing the fluctuations of one or more exchange rates is daunting. Nonetheless, the results of Table 4 indicate that the SNB in the past decade was unable to induce same-day directional moves to the Swiss Franc or to reduce excessive market volatility. On the contrary, as shown in Table 4, no discernible appreciation or depreciation of the CHFUSD was registered by our estimates of Eq. (2), nor did the volatility decrease in days when those official interventions were observed. Nonetheless, these actions had a clear impact on market liquidity and transaction costs. In fact, the mean absolute spread increased by 0.167 basis points when the SNB was selling USD to buy CHF and declined by 0.254 basis points when the SNB was engaged in sales of CHF. This last value is however not statistically significant, given the relative scarcity of such events in our sample.

Naranjo and Nimalendran (2000), using a model of official intervention, market-making, and information asymmetry, argue that unexpected Central Bank transactions, because hidden among the larger population of uninformed trades, induce dealers to increase their spreads. However, a change in the bid-ask spread in days when official SNB interventions were recorded does not easily reconcile with this explanation, for CHFUSD dealers know when the SNB hits their quotes, and the nature of its action is revealed to them immediately afterwards and quickly divulged to the rest of the market. More generally, Dominguez (1999) observes that, although official interventions, as any other foreign exchange transactions, are officially anonymous, most Central Banks have developed relationships with dealers that allow them to know their identity as a counterparty. In the spirit of Evans and Lyons (2001), it is instead more likely that Central Bank intervention creates (order flow) information asymmetry between the few dealers who are hit by the official intervention and learn about its direction and magnitude, and the rest of the dealers who only slowly acquire this information from rumors and their own order flow. The latter would be the dealers posting wider bid-ask spreads, in order to be compensated for the losses that they expect to suffer from trading with the former category of better informed dealers. In support of this analysis is the fact that, when the (more numerous) uninformative customer transactions are taken into account and Eq. (2) is estimated, the changes in spread are not statistically significant from zero. Apparently, in those circumstances the market does not seem to attribute any value to order flow information resulting from transacting those trades.

As suggested by Pasquariello (2001b), it is also possible that intervention trades alter market liquidity by pushing risk-neutral dealers' inventories away from desired levels. At the market's relative demand elasticity in place at or around the time when official interventions were occurring, market-makers might have been able to absorb those additional amounts, and to induce 
the necessary rebalancing in the investors' portfolios just by altering their spreads. Another plausible explanation for the findings presented in Table 4 is in forex dealers being risk-averse. Official interventions increase exchange rate volatility, and dealers would react to it by widening their spreads (e.g., Stoll (1978)). Along these lines, because customer transactions do not appear to have any significant impact on the market's dispersion of beliefs, bid-ask spreads should not (and do not) vary. More work to clarify the nature of this effect is clearly warranted. In the next section we devise and estimate a simple model that allows us to assess the relative importance of each of these somewhat conflicting interpretations of our results.

Thus, absolute spreads tend to be higher in days when dollar sales on behalf of the Swiss Central Bank were executed, and lower in days when the SNB was instead selling CHF. Are those changes in the spread economically significant as well? We compute the average annualized impact of SNB interventions on transaction costs for different estimates of daily CHFUSD turnover around its mean for 1998. Because we are unable to discern how much of that turnover is due to sales or purchases of USD, we divide each of those amounts in half (as in Naranjo and Nimalendran (2000)) and multiply them by the average increase in the spread for each million of USD bought or sold, i.e., by $\theta_{0}$ from Table 4 . These values are then multiplied by 252 (trading days) to provide annualized estimates.

We report the results of such computations in Table 5. For daily turnover from $\$ 50$ to $\$ 200$ billion and in the more recurrent scenario of official USD sales/CHF purchases on behalf of the SNB, the average increase in transaction costs borne by the community of forex investors ranges from over $\$ 100$ to almost $\$ 420$ million. These cost estimates are not negligible, especially in a highly efficient market like the one for the CHFUSD spot exchange rate. Moreover, these values clearly ignore the potential anticipation and persistence of such effects for days before and after the intervention (an issue we will soon address), the economic loss stemming from the increase in exchange rate volatility for risk-averse investors, the reduction in market liquidity measured by the fewer posted quotes on the Reuters terminals, and the cost of dealers' and speculators' portfolio rebalancing efforts induced by official interventions. Transaction costs instead decline by $\$ 160$ to $\$ 640$ million when the SNB is engaged in USD purchases/CHF sales. Assuming that the market's order flows are relatively insensitive to a change in spread of about a quarter of one basis point, these amounts represent a net loss for the dealers, hence a net gain for the population of investors.

The average frequency with which bid and ask prices are posted on the Reuters terminals, $d_{t}$, uniformly and significantly decreases by half a minute, while the average number of quotes posted in a day significantly increases, 
although only by about 100 units, in days when official interventions are executed, even after controlling for the increase in the daily number of quotes registered on the FXFX page between 1990 and 1998. This evidence suggests that the arrival of new quotes clusters in shorter intervals of the day when the SNB is trading, and is consistent with SNB actions inducing more dispersion of beliefs among market participants. Indeed, in those circumstances, the market would be more (and not less) uncertain about the true value of the currency, portfolio rebalancing activity would intensify, and the dealers would refresh their quotes more often until an implicit consensus is reached over where the exchange rate should be. That information asymmetry and riskaversion, but not inventory considerations are more likely explanations for these effects is reinforced by the fact that customer transactions have no statistically significant impact on $d_{t}$ and $f_{t}$, although those trades are similar in average daily magnitude to official interventions (according to Table 2).

\subsection{Cumulated impact of SNB actions}

We now investigate the questions of whether the market anticipates the arrival of official interventions, hence inducing currency fluctuations, higherthan-usual exchange rate volatility, lower market liquidity, and bigger transaction costs prior to when SNB-originated trades are executed, and of whether such effects persist afterwards. We do so by estimating Eq. (3) for the three basic sets of official interventions, $h=I, I>0$, and $I<0$, for $I \& C$, and for the three control categories made of customer transactions, $C, C>0$, and $C<0$. Evidence from the set of events in $I \& C$ should reinforce the results from the analysis of the event type $h=I>0$, for all the official transactions there recorded were dollar purchases as well. We consider leads and lags of $K=8$ trading days with respect to the event day $t .{ }^{13}$ From the estimated coefficients we then compute measures of cumulated impact $b_{-w}^{h}$ for each variable and for each event type $h$, and plot them in Figure 4.

Overall, our evidence suggests that SNB interventions have an asymmetric impact on all the variables of interest, with official dollar purchases, recorded in the subsets $h=I>0$ and $h=I \& C$, being the events inducing the biggest reaction in returns, in measures of exchange rate volatility and trading intensity, and in transaction costs. Official CHF sales by the SNB are not only the least frequent events in our sample but also the ones most likely

\footnotetext{
${ }^{13}$ We chose $K=8$ because each of the two ensuing symmetric intervals including the event day is going to cover a temporal window of approximately two weeks, if we account for potential weekday holidays. We also estimated Eq. (3) for larger and shorter numbers of leads and lags, but our results were not meaningfully affected.
} 
to generate greater dispersion of beliefs among market participants. In these cases in fact the SNB was attempting to weaken its target exchange rate against a historically strong currency (over the sample period) like the USD. Hence, it should probably not be surprising that those are the circumstances in which the market adjusts most abruptly to their occurrence.

Figure 4a, displaying the cumulated impact of both interventions and customer transactions on daily aggregate midquote returns $r_{t}$, sheds some light on the mechanics and effectiveness of SNB interventions. We start from the left panel of Figure 4a, where $h=I, I>0, I<0$, and $I \& C$. Between 1986 and 1996, the Swiss Central Bank purchased USD (CHF) in reaction to a steadfast average appreciation (depreciation) of about $1 \%$ in the domestic currency. On average, the market did not anticipate the incoming interventions before the SNB-originated transaction was actually executed. Indeed, cumulated impact coefficients $\mathfrak{b}_{-w}^{h}$ for $h=I$ on daily returns $r_{t}$ move in the direction of the intervention only starting with $\otimes_{0}$. Nonetheless, independently from their sign, SNB interventions produced relevant and persistent effects on the CHFUSD. In other terms, the market's reaction to such actions, measured by the estimated sums $b_{-w}^{h}$ for $w<0$ and $h=I$, or $h=I \gtrless 0$, was prolonged over time; more specifically, the Swiss Franc weakened after a purchase of USD or strengthened after a sale of USD for up to five days following the official intervention. Thus, the SNB was relatively successful in slowing or reversing a previously observed trend in that key currency rate, even though its transactions were generally smaller than typical forex trades.

This evidence also suggests that any new information resulting from those interventions does not immediately disseminate to all market participants, as in Peiers (1997) for the Deutschemark/USD exchange rate. That information should play an important role in explaining these findings, in particular that the signaling channel of intervention effectiveness of Mussa (1981) and Bhattacharya and Weller (1997) should be invoked is confirmed by the evidence offered by ex post uninformative customer transactions, in the right panel of Figure 4a. The cumulative impact of those trades on midquote returns is economically negligible, although their average intraday and daily signed magnitudes are similar to the corresponding intervention amounts. If imperfect asset substitutability at the market or dealer level was relevant to the effectiveness of Central Banks' attempts to manage the fluctuations of their domestic currencies, as argued by Evans and Lyons (2001), even ex post uninformative actions by the SNB should affect dealers' inventories, interdealer order flow, and eventually exchange rate returns, through market participants' efforts at rebalancing their portfolios. However, by looking at the small values estimated for $b_{-w}^{h}$ at or around the time when these trans- 
actions were recorded, there is no evidence of such an effect. Cumulated returns actually decrease before a customer purchase of dollars, but increase soon afterwards; vice versa, $b_{-w}^{h}$ increases before customer sales of dollars and declines significantly few days after their execution. Rather, the SNB, by selling the domestic currency when strong and buying it when weak, showed excellent market-timing ability in trading aimed at preserving its wealth and/or at replenishing its reserves.

In the left panels of Figures $4 \mathrm{~b}$ and $4 \mathrm{c}$, exchange rate volatility, measured by both $\left|r_{t}\right|$ and $r_{t}^{2}$, appears to pick up as soon as the market learns of an incoming intervention, or as soon as dealers and investors raise their subjective probabilities of observing the SNB in action in the immediate future. $^{14}$ Uncertainty surrounding scopes, time horizon, and motives of those interventions justifies increased market uncertainty and more reluctancy to advertise new quotes up to three days before their occurrence. However, in the days immediately preceding the event date, clearer anticipation of future SNB activity appears to induce dealers to update their posted quotes more (and not less) frequently, as indicated by the sharp and persistent decline in cumulated $b_{-w}^{h}$ for $d_{t}$ (in the left panel of Figure $4 \mathrm{f}$ ), and/or to market their availability to trade more aggressively by posting more quotes, as shown by the increase in $f_{t}$ in the left panel of Figure $4 \mathrm{~g}$.

Nonetheless, the arrival of SNB-originated trades does very little to reduce the dispersion of beliefs among market participants, for the ex post realized return volatility actually increases sharply and stays high for many days following the event date. This is true especially for official dollar purchases $(I>0)$, i.e., for the interventions that we expect to be the most likely to puzzle dealers and investors. No impact on $\left|r_{t}\right|, r_{t}^{2}, d_{t}$ and $f_{t}$ is induced by uninformative customer transactions, as shown in the right panels of Figures $4 \mathrm{~b}, 4 \mathrm{c}, 4 \mathrm{f}$ and $4 \mathrm{~g}$, offering further support to information asymmetry (among market participants) and risk-aversion considerations, but not to inventorybased models in explaining dealers' behavior in the forex market in proximity of Central Bank interventions.

Not only do dealers revise indicative bid and ask prices on the FXFX page more often, but they also widen their posted absolute and proportional spreads almost simultaneously with the increase in the exchange rate volatil-

\footnotetext{
${ }^{14}$ The dynamics of $b_{-w}^{\mathrm{h}}$ for $\left|r_{\mathrm{t}}\right|$ and $r_{\mathrm{t}}^{2}$ cannot be explained by a positive or negative drift potentially induced by the intervention to the underlying exchange rate process. In fact, when we estimate Eq. (3) for a more traditional measure of dispersion of tick-by-tick CHFUSD returns from their daily intraday mean, the standard deviation of $r_{\mathrm{t}_{\mathrm{n}}}$ over day $t$, the resulting dynamics of the cumulated impact of intervention (not reported here) are similar to the ones displayed by absolute and square returns in Figures $4 \mathrm{~b}$ and 4c.
} 
ity, up to a cumulated amount of almost 1 basis point in the case of $I>0$. Spreads do not appear to return to previous levels even 8 days after the SNB trades have been executed. Hence, Figures $4 d$ and 4 e suggest that the effectiveness of SNB interventions is accompanied not only by greater exchange rate volatility but also by higher transaction costs, i.e., by costs borne by the population of risk-averse investors for a relatively long period of time. Using daily currency data, GARCH specifications, and implied volatility data from American call options, Dominguez (1998) also shows that G-3 intervention policies between 1977 and 1994 generally increased exchange rate volatility, particularly if secret. Secrecy, however, cannot be invoked to explain our findings, as all SNB operations in our sample became public knowledge in the market immediately after their execution. Instead, the long-lasting surge in volatility and spreads following those transactions could be the result of protracted uncertainty over sign, size, and timing of future interventions and, more generally, of the evolution of (possibly heterogeneous) expectations about future SNB activity in the CHFUSD market. Indeed, such slow resolution of uncertainty and disagreement surrounding the scope of past and incoming interventions might also explain the post-event drift in returns observed in Figure 4a. We explore in greater detail the significance of potential misinformation stemming from the actions of the SNB in the next section.

The model of Guembel and Sussman (2001) offers an alternative, intriguing interpretation of Figure 4. Although most commentators and central bankers seem to agree that active currency management policies should decrease forex volatility and deter speculation, Guembel and Sussman show that these objectives may instead be mutually incompatible. This would be the case when the domestic monetary authority can curb speculators' profits only at the cost of increasing the currency's responsiveness to order flow, hence inducing higher variation in intraday exchange rate returns. Along these lines, it might be argued that the relative effectiveness of SNB trades in interrupting and/or reverting recent excess cumulated CHFUSD depreciation/appreciation (evident from Figure 4a), the excess return volatility, and the sharp increase in transaction costs in the days surrounding those transactions (in Figures 4b, 4c, and 4d) all arise from the optimal resolution of a trade-off between reducing speculation (or making it less profitable) and smoothing fluctuations of the domestic currency. Unfortunately, without additional evidence on the intensity of speculative activity on the Swiss Franc in proximity of SNB interventions, this claim cannot be further substantiated.

As previously anticipated, bid-ask spreads do not seem to react to signed or unsigned customer transactions, regardless of their size. This also corroborates our (at this stage still preliminary) assertion that inventory considerations play only a secondary role in explaining the impact of SNB actions 
on the process of price formation in the CHFUSD market, in particular on the dynamics of market liquidity and transaction costs. In the next section, a simple model is developed and estimated to evaluate more accurately the relative importance of information, risk-aversion, or liquidity-based interpretations of the impact of Central Bank intervention on the bid-ask spread, as a proxy for the gains/losses incurred by the population of investors and dealers in proximity of SNB trades.

\section{Liquidity shocks' decomposition}

In the previous section we have shown not only that the Swiss monetary authority appears to have been generally successful in reversing existing market trends for the domestic currency, albeit less so in smoothing its fluctuations or in reducing its variability, but also that absolute and proportional spreads for the CHFUSD may increase or decrease in a (statistically and economically) significant fashion in proximity of SNB interventions. In many cases these changes preceded the actual intervention event and were protracted in time. For example, in the right panels of Figures $4 \mathrm{~d}$ and $4 \mathrm{e}$ both $S_{t}$ and $s_{t}$ rise after official USD purchases and remain high for many days following those trades.

Changes in market liquidity and transaction costs were typically accompanied by greater realized exchange rate volatility and more frequent updates of indicative quotes on the Reuters terminals, thus suggesting that SNB-originated trades did spark, rather than placate, uncertainty among forex speculators and dealers. We have also seen that, in the control sample made of ex post uninformative customer transactions, the cumulative impact of SNB actions on returns, spreads and proxies for exchange rate volatility was in most cases negligible. This led us to suggest a more limited role for inventory-based explanations of Central Bank effectiveness in the forex market at or around the time when official interventions were executed.

Overall, this evidence seems to indicate that, independently from their effectiveness, attempts by the SNB to manage the fluctuations of the CHFUSD do affect significantly market liquidity, and that the resulting changes in transaction costs are borne alternatively by dealers (when spreads are tighter) or by the population of investors at large (when spreads are instead wider). It is then of interest to determine the relative importance of increasing dispersion of beliefs among market participants, information asymmetry, inventory, or risk-aversion considerations in explaining the impact of Central Bank interventions on the forex market's ability to accommodate trades and news with the least impact on transaction costs. 
As mentioned in Section 3, from the economic and financial literature three main basic explanations can be identified of why Central Bank intervention on the spot exchange rate might significantly affect observed bid-ask spreads in the forex market. The first one relies on the role of information. According to Naranjo and Nimalendran (2000), unexpected intervention is a source of information asymmetry between dealers and the Central Bank, thus of higher spreads. Additionally, Peiers (1997) observes that information generated by the intervention dissipates very slowly. Hence, more general information asymmetries may arise between any agent that, as a consequence of the intervention itself, has acquired an informational advantage with respect to the rest of the market and the broader population of dealers, therefore inducing the latter to widen their spreads. Grossman (1988) suggests that, following the release of new stabilizing information, transaction costs should decline. Alternatively, Stein (1987) emphasizes the destabilizing role of misinformation stemming from increasing information heterogeneity. Copeland and Friedman (1987) then show that bid-ask spreads are positively related to the level of misinformation existing in a market. Thus, official interventions could also dampen (augment) the wedge between bid and offer exchange rates if they reduce (raise) the degree of information heterogeneity or misinformation prevailing at or around the time these transactions were executed.

Second, it is argued for example by Evans and Lyons (2001) that, because of the imperfect substitutability of otherwise identical interest-bearing assets denominated in different currencies, interventions may have a liquidity effect on the forex markets. In fact, depending on the existing demand elasticity of investors and market-makers, forex dealers may have to increase or decrease not only their posted quotes but also their spreads to clear the market. Moreover, as a consequence of the intervention and/or of the ensuing portfolio rebalancing efforts by investors and speculators, dealers' inventories may be pushed away from certain desired levels related to their risk-aversion and to given capital constraints. Therefore, forex market-makers might modify bid and ask prices asymmetrically in order to induce their inventories to revert toward those optimal levels, along the lines of Stoll (1978), Amihud and Mendelson (1980), and Pasquariello (2001b).

Finally, related to the role of information is the observation that official interventions may be suggestive of more general shifts in some of the fundamental characteristics of the exchange rate, thus often greatly affecting exchange rate volatility, hence the bid-ask spreads posted by risk-averse dealers. We have already shown, for example in Figures $4 \mathrm{~b}$ and $4 \mathrm{c}$, that in our sample SNB-originated trades frequently had a destabilizing effect on ex post measures of market variation. Payne and Vitale (2001) further find that volatility may rise also when transactions executed on behalf of the Central 
Bank increase the heterogeneity of beliefs among market participants.

\subsection{The model}

In the remainder of this section, we want to evaluate the relative importance of these considerations in explaining the impact of Central Bank's actions in the spot exchange rate market on the absolute spread $S_{t}$ as a measure of market liquidity and transaction costs, i.e., in explaining observed changes in the variable $S_{t}, \Delta S_{t}$, at or around the time when interventions were executed. In this analysis we ignore proportional spreads, for we deem shocks to $s_{t}$ less adequate proxies for changes in liquidity induced by official interventions. Indeed, as shown in Figure 4a, SNB interventions affect significantly CHFUSD cumulated returns, hence the midquote exchange rate representing the implicit "denominator" in $s_{t}$. Such eventuality could bias any resulting inference on transaction costs based on the dynamics of $\Delta s_{t}$.

In order to identify the components of those changes due to information, liquidity, or volatility, we use a simple model originally developed by $\mathrm{Fe}-$ denia and Grammatikos (1992). We start by assuming that, after controlling for weekday and long-term effects, absolute spreads observed in proximity of the intervention event $i, S_{i}$, are a function of two main by-products of the intervention itself, liquidity $L_{i}$ and information $I_{i}$, i.e., that

$$
S_{i}=S_{i}\left(L_{i}, I_{i}\right) .
$$

Hence, we can approximate the change in spread due to intervention-induced liquidity or information shocks as

$$
\Delta S_{i}=\frac{\partial S_{i}}{\partial L_{i}} \Delta L_{i}+\frac{\partial S_{i}}{\partial I_{i}} \Delta I_{i} .
$$

We have mentioned above that information shocks resulting from official interventions might condition the dynamics of bid-ask spreads in two general ways. First, the arrival of information may affect the current exchange rate volatility, $\Delta V_{i}$, and in turn the spread. Second, Central Bank interventions may induce a higher or lower degree of information heterogeneity, $H_{i}$. Using experimental studies, Copeland and Friedman (1987) find that spreads tend to increase when dealers are exposed to price uncertainty ensuing from higher information heterogeneity among market participants. Therefore, we claim that $I_{i}=I_{i}\left(\Delta V_{i}, H_{i}\right)$. This clearly implies that

$$
\Delta I_{i}=\frac{\partial I_{i}}{\partial \Delta V_{i}} \Delta\left(\Delta V_{i}\right)+\frac{\partial I_{i}}{\partial H_{i}} \Delta H_{i} .
$$


Substituting Eq. (6) into Eq. (5) a new expression for $\Delta S_{i}$ then follows:

$$
\Delta S_{i}=\frac{\partial S_{i}}{\partial L_{i}} \Delta L_{i}+\frac{\partial S_{i}}{\partial \Delta V_{i}} \Delta\left(\Delta V_{i}\right)+\frac{\partial S_{i}}{\partial H_{i}} \Delta H_{i}
$$

Eq. (7) decomposes observed changes in the spread around an intervention event $i$ into perturbations potentially related to the intervention itself, i.e., shocks in market liquidity factors, $\Delta L_{i}$, changes in exchange rate volatility, $\Delta\left(\Delta V_{i}\right)$, and increased or decreased dispersion of beliefs among market participants, $\Delta H_{i}$.

To make this expression operational without developing a more formal model for the functional forms $S_{i}()$ and $I_{i}()$, we need to specify measures for the corresponding shock variables and to approximate the partial derivatives in Eq. (7). Based on the analysis of the previous subsections, we define $\Delta S_{i}$ in two ways, depending on whether we focus on the aggregate average impact of the intervention event over a prespecified interval surrounding the date when the $i$-th intervention occurred, $t_{i}$, or on the sequential impact of the same event over each of the days in the same time interval. In the first case we compute $\bar{S}_{i}$ as the average absolute spread over a window of 17 days surrounding the event date $t_{i}$, i.e., over the interval $\left[t_{i}-8, t_{i}+8\right]$, as in Eq. (3). In order to measure the magnitude of the impact of official intervention while at the same time controlling for the presence of overlapping intervention intervals in the sample, we define a benchmark absolute spread $\bar{S}_{i}^{B}$ as the mean value for $S_{i}$ over the first 20 days preceding the third to last day before the event window $\left[t_{i}-8, t_{i}+8\right]$ that do not contain any other past corresponding event window day. If we label such days with $a^{*}$ symbol, then we have that $\bar{S}_{i}^{b}={ }_{j=-30^{*}}^{-\mathrm{Pl}^{*}} \frac{S_{\mathrm{i}}(j)}{20}$, where $S_{i}(j)$ is the absolute spread observed at time $t_{i}+j$. Finally, our proxy for intervention-induced shocks on $S_{i}$ for each event $i$ is given by $\Delta S_{i}=\bar{S}_{i}-\bar{S}_{i}^{b}$.

The evidence from Figures $4 \mathrm{a}$ to $4 \mathrm{~g}$ suggests that investors and dealers may anticipate the occurrence of a transaction on behalf of the Central Bank and immediately discount it in prices and quotes even before that transaction has actually been executed, and that the effects of the intervention may persist for several days over the process of price formation in the currency markets. Hence, in the second case we define our shock variable for absolute spreads in proximity of the $i$-th intervention as $\Delta S_{i}(j)=S_{i}(j)-\bar{S}_{i}^{b}$ for each day in the interval $\left[t_{i}-8, t_{i}+8\right]$. In Figure 5 we display averages for those shock measures, $\overline{\Delta S_{i}(j)}$, computed for each of the corresponding leads and lags $j$ from the event date $t_{i}$, i.e., $\forall j \in[-8,8]$, over subsamples of event types $h=I, I>0, I<0, C$, and $I \& C$. The dynamics of Figures $4 \mathrm{~d}$ and 
5 are strikingly similar. Indeed, consistently with Figure 4d, shocks to the absolute spread $S_{i}(j)$ (except around customer transactions) are positive, large, and increasing a few days before the intervention actually occurred, in particular when the SNB was purchasing dollars, but decline steadily soon afterwards.

We now focus on the variables on the right side of Eq. (7). In the equilibrium spread model of Cohen et al. (1981), spreads are inversely related to liquidity, i.e., $\partial S_{i} / \partial L_{i}<0$, and the marginal reduction in transaction costs from increased liquidity is decreasing, that is $\lim _{L_{\mathrm{i}} \rightarrow \infty} \partial S_{i} / \partial L_{i}=0$. As in Fedenia and Grammatikos (1992), we assume that $\partial S_{i} / \partial L_{i} \approx \beta_{i} / L_{i}$, where $\beta_{i}<0$, and that the spread observed before the intervention, our benchmark variable $\bar{S}_{i}^{b}$, is a good proxy for the inverse of liquidity. This implies that $\partial S_{i} / \partial L_{i} \approx \beta_{i} S_{i}$. Finally, we subsume the change in liquidity $\Delta L_{i}$ in a parameter so that the liquidity term in Eq. (7) becomes

$$
\frac{\partial S_{i}}{\partial L_{i}} \Delta L_{i} \approx \beta_{i} S_{i} \Delta L_{i}=\lambda_{1 i} \bar{S}_{i}^{b}
$$

According to Stoll (1978) and, more recently, Saar (2000a, b), spreads are positively related to changes in volatility, i.e., $\partial S_{i} / \partial \Delta V_{i}>0$. In the already mentioned study by Copeland and Friedman (1987), spreads also seem to increase in correspondence with higher dispersion of beliefs among market participants, that is $\partial S_{i} / \partial H_{i}>0$. For simplicity, we assume that the relationship between spread and volatility is roughly linear, i.e., that $\partial S_{i} / \partial \Delta V_{i} \approx a_{i}+b_{i} \Delta V_{i}$. Therefore, if we define $\Delta\left(\Delta V_{i}\right)=c_{i} \Delta V_{i}$, the volatility part in Eq. (7) becomes

$$
\frac{\partial S_{i}}{\partial \Delta V_{i}} \Delta\left(\Delta V_{i}\right)=\lambda_{2 i} \Delta V_{i}+\lambda_{3 i}\left(\Delta V_{i}\right)^{2}
$$

where $\lambda_{2 i}=a_{i} c_{i}$ and $\lambda_{3 i}=b_{i} c_{i}$. Finally, we assume that $\partial S_{i} / \partial H_{i}=\lambda_{0 i}$. Our basic measurable cross-event expressions from the general setting of Eqs. (5) to (7) for both $\Delta S_{i}$ and $\Delta S_{i}(j)$ are then given by

$$
\Delta S_{i}=\lambda_{0 i}+\lambda_{1 i} \bar{S}_{i}^{b}+\lambda_{2 i} \Delta V_{i}+\lambda_{3 i}\left(\Delta V_{i}\right)^{2}+\varepsilon_{i}
$$

and

$$
\Delta S_{i}(j)=\lambda_{0 i}+\lambda_{1 i} \bar{S}_{i}^{b}+\lambda_{2 i} \Delta V_{i}(j)+\lambda_{3 i}\left(\Delta V_{i}(j)\right)^{2}+\varepsilon_{i}(j),
$$

respectively, for $j \in[-8,8]$ and for all the selected Central Bank actions $i$. Because we want the regressors to measure shocks in information, volatility, and liquidity induced by the intervention activity, the regressors $\Delta V_{i}$ 
and $\Delta V_{i}(j)$ are measured with respect to a benchmark $\bar{V}_{i}^{b}$ constructed over the same interval of time preceding the event interval we specified for the dependent variables. Hence, $\Delta V_{i}=\bar{V}_{i}-\bar{V}_{i}^{b}$ and $\Delta V_{i}(j)=V_{i}(j)-\bar{V}_{i}^{b}$.

We also consider the possibility that two additional variables, a shock in the number of posted quotes at or around the intervention day $\Delta f_{i}=\bar{f}_{i}-\bar{f}_{i}^{b}$ $\left(\Delta f_{i}(j)=f_{i}(j)-\bar{f}_{i}^{b}\right)$, and a shock in the mean rate of arrival of new quotes on the Reuters terminals $\Delta d_{i}=\bar{d}_{i}-\bar{d}_{i}^{b}\left(\Delta d_{i}(j)=d_{i}(j)-\bar{d}_{i}^{b}\right)$, impact $\Delta S_{i}$ $\left(\Delta S_{i}(j)\right)$. Pasquariello (2001b) argues that the absolute impact of official interventions on bid-ask spreads is greater when forex dealers hold less market power, because more of the profits and losses they experience from such actions have to be passed onto the population of investors. Saar (2000a) suggests that, when dealers compete among each other for the incoming trade, bid-ask spreads should decline. Hence, if we interpret the number of daily posted quotes $f_{i}$ during intervention periods as measuring the intensity of competition in the forex market, then positive values for $\Delta f_{i}$ should be accompanied on average by a decline in absolute spreads.

Grossman and Miller (1988) introduce a new temporal dimension to the concept of liquidity, by suggesting that the possibility of immediate execution of a trade should be valuable to investors. Thus, a market is liquid if, when an investor is willing to transact now rather than later, prices and spreads he has to face have not been revised too unfavorably in response to his quest for immediacy. Grossman and Miller's model derives the intuitive result that the greater the number of speculators not willing to postpone a transaction, the greater the liquidity of a market. Cohen et al. (1981) relate the concept of liquidity to the degree of market thinness, as measured by the inverse of the order arrival rate. Along these lines, we argue that negative (positive) spread changes induced by more (less) intense and frequent trading activity in proximity of an intervention (measured by negative (positive) shocks in the average time between consecutive posted quotes, $\Delta d_{i}$ ), after controlling for the role of market uncertainty, inventory considerations, and information, represent such an additional measure of (il)liquidity induced by an event like a Central Bank-originated trade. ${ }^{15}$

We evaluate the relevance of these considerations by proposing the fol-

\footnotetext{
${ }^{15}$ It is however necessary to emphasize that the variables $f_{\mathrm{t}}$ and $d_{\mathrm{t}}$ may be biased or inaccurate measures of trading intensity, as argued for example by Dacorogna et al. (2001). Indeed, simultaneous or automatic price quotation by dealers, delays in refreshing posted quotes during periods of high activity, and quotes' heterogeneous representativeness should suggest some caution in interpreting $f_{\mathrm{t}}$ and $d_{\mathrm{t}}$ as proxies for volume, competition, or market share in the empirical analysis that follows.
} 
lowing extensions of Eqs.(10) and (11):

$$
\Delta S_{i}=\lambda_{0 i}+\lambda_{1 i} \bar{S}_{i}^{b}+\lambda_{2 i} \Delta V_{i}+\lambda_{3 i}\left(\Delta V_{i}\right)^{2}+\lambda_{4 i} \Delta f_{i}+\lambda_{5 i} \Delta d_{i}+\varepsilon_{i}
$$

and

$$
\begin{aligned}
\Delta S_{i}(j)= & \lambda_{0 i}+\lambda_{1 i} \bar{S}_{i}^{b}+\lambda_{2 i} \Delta V_{i}(j)+\lambda_{3 i}\left(\Delta V_{i}(j)\right)^{2}+ \\
& +\lambda_{4 i} \Delta f_{i}(j)+\lambda_{5 i} \Delta d_{i}(j)+\varepsilon_{i}(j),
\end{aligned}
$$

respectively.

Before commenting on the estimation of Eqs. (10) to (13), in the following list we provide a brief summary of the proposed interpretation and expected sign for each of the coefficients in the above regressions:

$\lambda_{0 i} \quad \mathrm{~A}$ proxy for the average change in transaction costs induced by a change in the dispersion of beliefs among market participants. From Copeland and Friedman (1987) we assume that $\partial S_{i} / \partial H_{i}>0$; hence, a positive (negative) estimate for this coefficient indicates that on average the degree of information heterogeneity, or what Stein (1987) calls misinformation, is higher (lower) during the intervention interval, i.e., that official interventions induce destabilizing (stabilizing) information.

$\lambda_{1 i} \quad$ A proxy for the average effect of any shock induced by official interventions to market liquidity on the bid-ask spread. Under the assumption that $\beta_{i}<0$, i.e., that spreads are inversely related to liquidity, then if the estimated coefficient is negative, interventions induce on average greater market liquidity and tighter spreads.

$\lambda_{2 i} \quad$ A measure of the relationship between changes in ex post market volatility accompanying transactions executed on behalf of the Central Bank and the bid-ask spread. As in Stoll (1978) and Saar (2000a, b), among others, we expect this relation to be positive, i.e., we expect a positive value for $\lambda_{2 i}$.

$\lambda_{3 i} \quad$ A measure of the degree of non-linearity of the relation between spread changes and exchange rate volatility. We do not formulate any ex ante prediction on this coefficient.

$\lambda_{4 i} \quad$ A measure of the impact on the bid-ask spread of more or less numerous quotes posted on average in the FXFX page during intervention intervals. If we interpret $\Delta f_{i}>0\left(\Delta f_{i}<0\right)$ as a proxy for increasing (decreasing) intensity of competition in the forex market, then positive values for $\Delta f_{i}$ should be accompanied on average by a decrease in the absolute spread. Therefore, $\lambda_{4 i}$ should be negative and significant. 
$\lambda_{5 i} \quad$ A measure of the relation between investors' need for immediacy (and dealers' ability to provide it) and the bid-ask spread. If we interpret $\Delta d_{i}$, the change in the rate at which quotes arrive to the Reuters screens during intervention periods, as a proxy for a shock to such immediacy induced by the occurrence of a SNB-originated trade, or as a proxy for a shock to market thinness, a positive and significant coefficient $\lambda_{5 i}$ represents a positive value of immediacy during the event


Grossman and Miller (1988).

\subsection{Model estimation and results}

We estimate Eqs. (10) to (13), with a standard GMM procedure, for the subsamples made of events $i$ (in chronological sequence) of type $h=I, I>0$, $I<0$, and $I \& C$. Then, in Tables $6 \mathrm{a}$ and $6 \mathrm{~b}$ we collect the resulting cross-

event parameters $\mathbb{1}_{0 i}$ to $\mathbf{R}_{5 i}$ when shocks to exchange rate volatility $\Delta V_{i}$ and $\Delta V_{i}(j)$ are approximated by the corresponding shocks to daily absolute returns $\left|r_{i}\right|$ and $\left|r_{i}(j)\right|$, respectively, and establish their statistical significance using Newey-West standard errors, because of evidence of residual autocorrelation and heteroskedasticity. ${ }^{16}$ We also consider the control sample of ex post uninformative customer transactions, i.e., the case in which $h=C$, in the last rows of Tables $6 \mathrm{a}$ and $6 \mathrm{~b}$. This allows us to gauge the importance of official interventions carrying information to the market, and to measure the relative significance of the relationship between measured spread shocks and changes in liquidity, information heterogeneity and volatility that those interventions induce relative to trades executed simply to replenish reserves.

The model appears to perform very well in explaining aggregate and single cross-event variation in positive and negative intervention shocks for absolute spreads $S_{i}$. We start with the analysis of the components of the aggregate impact variables $\Delta S_{i}$. Adjusted $R^{2} \mathrm{~s}$ are higher in the more frequent circumstances when the SNB was buying CHF and selling USD, ranging from as much as $72 \%$ for Eq. (10) to $84 \%$ for Eq. (12). The coefficient $\mathbb{1}_{1 i}$ is significantly negative in all cases. This corroborates Evans and Lyons (2001) in their claim that official interventions affect liquidity in the forex market. In particular, our evidence suggests that on average SNB-originated trades increased market liquidity and induced tighter spreads. The decline in spreads $\mathbb{1}_{1 i}$ is however always larger when the Central Bank is engaged in

\footnotetext{
${ }^{16}$ The same parameters, estimated computing $\Delta V_{\mathrm{i}}$ and $\Delta V_{\mathrm{i}}(j)$ with changes in the corresponding daily square return measures $r_{i}^{2}$ and $r_{i}^{2}(j)$, respectively, were very similar to the ones in Tables $6 \mathrm{a}$ and $6 \mathrm{~b}$ in both sign and significance. Therefore, they are not reported here but are available on request.
} 
dollar sales, suggesting that this type of trade has a bigger impact on market liquidity.

The coefficient representing the effect of volatility shocks on the absolute spread, $\mathbb{Q}_{2 i}$, has the expected positive sign in Table 6a. Hence, the increase in exchange rate volatility we observe in Figures $4 \mathrm{~b}$ and $4 \mathrm{c}$ at or around the time when SNB interventions are recorded appears to induce dealers to widen their spreads. Interestingly, estimated values for $W_{2 i}$ are highest when our previous measures of excess volatility are the lowest, that is, when the Swiss monetary authority was buying CHF. This suggests that the marginal effect on spread changes of volatility shocks is decreasing in their magnitude. That shocks in ex post measures of return variation have a non-linear impact on transaction costs is confirmed by the parameter $\mathbb{X}_{3 i}$ being statistically different from zero (and negative) in many of the subsamples considered in the analysis.

Table 6 a shows that, after controlling for changes in liquidity and volatility, absolute spreads increase in proximity of SNB interventions, i.e., $\mathbf{Q}_{0 i \mathrm{~s}}$ are positive, significant, and strikingly similar across most event types. Hence, transactions executed on behalf of the Swiss Central Bank had a destabilizing effect on the CHFUSD market, that is unrelated to the increase in volatility that typically accompanied these events. Although, as previously mentioned, it is possible that volatility shocks may be linked to information heterogeneity as well, the consistently positive intercepts in the estimation of Eqs. (10) and (12) suggest that currency management attempts by the SNB did induce misinformation among market participants at or around the time SNB-originated trades were recorded. Not surprisingly, the most effective interventions (according to Figure 4a), official USD purchases $(I>0$ and $I \& C)$, are also the ones inducing the least amount of misinformation in the CHFUSD market, i.e., the ones for which $\mathbb{Q}_{0 i}$ is small and not statistically different from zero in Table 6a.

Sign and significance of $\mathbb{W}_{0 i}$ to $\mathbf{Q}_{3 i}$ are unchanged, but their absolute magnitude is generally reduced after accounting for shocks in the number of new quotes appearing in the Reuters terminals during the event interval $\left(\Delta f_{i}\right)$ and in the average time elapsing between new quotes posted on the FXFX page $\left(\Delta d_{i}\right)$. Estimates of $\mathbf{Q}_{4 i}$ for the former are generally negative, but statistically different from zero only for $h=I \& C$, while estimates of $\mathbb{\$}_{5 i}$ for the latter are uniformly positive and significant at any confidence level. Evidence of $\mathbf{W}_{4 i}<0$ is weakly supportive of changes in transaction costs induced by changes in competition among dealers, measured by shocks to $f_{i}$, during the event period $\left[t_{i}-8, t_{i}+8\right]$. It in fact suggests that bid-ask spreads tend to tighten if, as it appears to be the case from Figure $4 \mathrm{~g}$, at or around the 
time when official interventions occur, more dealers appear to compete more intensely for the incoming trade by posting more quotes, independently from the direction of the SNB transaction, consistently with the findings of Saar (2000a) and Pasquariello (2001b).

Positive $\mathbb{Q}_{5 i}$ s seem instead to indicate that immediacy was valued positively during the intervention event intervals. We have seen in Figure $4 \mathrm{f}$ that the intensity of trading activity first increases and then declines in proximity of SNB interventions. Indeed, dealers' quotes are in fact posted at a slower and slower pace in the days immediately preceding the intervention, but $d_{t}$ remains high for many days afterwards only when the SNB sold CHF. If we accept the interpretation of $d_{i}$ as a proxy for availability of immediacy in the market, or simply for market thinness, then we can argue that during intervention periods the ability to trade promptly appeared to be significantly affected, and that these changes were reflected first in higher and then in lower transaction costs borne by the population of investors at large.

When the single shock variable $\Delta S_{i}(j)$ is considered, and Eq. (11) is estimated in Table $6 \mathrm{~b}, \mathrm{Q}_{0 i}$ is still positive and bigger in magnitude in the subsample of SNB-originated sales of USD, suggesting that heterogeneity of beliefs arises and persists during the entire interval surrounding official interventions. Unfortunately, in many cases the corresponding parameters for liquidity and volatility, $\mathbb{1}_{\mathbf{1}}$ and $\mathbf{X}_{2 i}$, are not significant and do not display the expected sign. Nonetheless, the performance of the model is clearly improved, and in particular $\mathbb{Q}_{1 i}$ and $\mathbb{W}_{2 i}$ become significant and have the expected sign, by the inclusion of the two additional proxies for liquidity shocks, $\Delta f_{i}\left(\Delta f_{i}(j)\right)$ and $\Delta d_{i}\left(\Delta d_{i}(j)\right)$, i.e., by the estimation of Eq. (13). This is occurring because the cross-event series of shocks in Eqs. (11) and (13), made of each of the days in the interval surrounding the intervention event date $t_{i}$ (i.e., in $\left[t_{i}-8, t_{i}+8\right]$ ) are characterized by more noise than the corresponding mean series $\Delta S_{i}$. Hence, adding shocks in the average duration between consecutively posted quotes and in the daily number of quotes' arrivals appears to control for fluctuations in $\Delta S_{i}(j)=S_{i}(j)-$ $\bar{S}_{i}^{b}$ that did not appear in the aggregate measure $\Delta S_{i}=\bar{S}_{i}-\bar{S}_{i}^{b}$, which we use as a dependent variable in Eqs. (10) and (12). The coefficients $\mathbb{Q}_{0 i}$ to $\mathbb{Q}_{5 i}$ of Eq. (13) in Table $6 \mathrm{~b}$, from the decomposition of the shock variable $\Delta S_{i}(j)$ over each of the event interval days $j$, are consistent in sign, magnitude, and significance with the parameters of Eq. (12) obtained from the analysis of average changes $\Delta S_{i}$ in Table 6a. For example, the parameter $\mathbb{Q}_{4 i}$ is now negative and significant for each of the events $h$ under investigation. This confirms the robustness of those estimates (and of the ensuing interpretations) to the degree of finesse by which variables' shocks 
in proximity of interventions are examined.

Overall, the results reported in Tables $6 \mathrm{a}$ and $6 \mathrm{~b}$ emphasize the role played not only by changes in market liquidity but also by information shocks induced by the intervention, whether increasing the heterogeneity of beliefs among investors and dealers or raising exchange rate volatility, in explaining the increase in transaction costs that accompanies most Central Bank actions. The estimation of Eqs. (10) to (13) for the subsample made of intervals during which the SNB executed customer transactions offers additional support for this claim. Customer transactions are ex post uninformative, thus it should not be surprising that the coefficients for volatility shocks, $\mathbb{Q}_{2 i}$ and $\mathbf{X}_{3 i}$, and misinformation, $\mathbb{Q}_{0 i}$, are either insignificant or much smaller than their intervention counterparties. ${ }^{17}$ Estimates for $\mathbf{R}_{1 i}, \mathbf{Q}_{4 i}$, and $\mathbf{W}_{5 i}$ are instead significant and of the expected sign, suggesting that those trades, of average size similar to that of most interventions, have some impact on market liquidity, and in the direction proposed by the theory.

\section{Size, trend, and expectations}

In the analysis of the previous sections, we have classified SNB interventions and customer transactions merely according to their sign. Whether an official intervention is to buy or sell the domestic currency is however not the only distinguishing characteristic on which the economic and financial literature has focused its attention. In particular, three main features of such transactions have been explored by both theoretical and empirical studies on Central Banks' attempts at managing exchange rates.

The first of these features is size. There seems to be widespread agreement among researchers and practitioners, although with scant evidence, that size should be relevant in explaining differential effects of interventions on currency returns, return volatility, and market liquidity. In the context of a trading model à la Lyons (1997), a large order from the domestic monetary authority is just another hot potato to be passed from one dealer to the other in the forex market, as in Evans and Lyons (2001). Along those lines, Pasquariello (2001b) shows that the effect of currency management policies on quotes and absolute and proportional spreads depends crucially not only

\footnotetext{
${ }^{17}$ Nonetheless, $\mathbb{0}_{0 \mathrm{i}}$ may still be positive when $h=C$ because the corresponding transactions, although ex-post uninformative, are potentially informative ex-ante. In fact, as we already mentioned, dealers do not know the nature of the trade they just concluded with the monetary authority counterpart until after the transaction has been executed. The estimate for $Q_{0 \mathrm{i}}$ would then be capturing this form of ex-ante uncertainty, or misinformation among market makers.
} 
on the sign but also on the magnitude of Central Bank-originated trades when competing risk-neutral dealers attempt to avoid an expected drift in their inventories. From a different perspective, Bhattacharya and Weller (1997) and Vitale (1999) observe that large interventions, because generally more expensive than small ones, should be expected to have a bigger signaling impact on the domestic exchange rate. Payne and Vitale (2001) find some empirical support for a positive relationship between the magnitude of official SNB transactions and intraday CHFUSD returns, when those are computed over consecutive fifteen-minute intervals.

The second feature is market momentum. Studies by Dominguez and Frankel (1993) and Lewis (1995) reveal that most recorded official interventions appear to be aimed at preventing a key exchange rate from moving away from some target level. ${ }^{18}$ Dominguez (1999) and Payne and Vitale (2001) emphasize that calming otherwise disorderly markets is also a likely priority for a Central Bank. In practice, this implies that domestic monetary authorities often trade currencies in order to resist or reverse an existing trend in their key exchange rates. Conventionally, interventions going in the direction of the trend are known as chasing the trend, while interventions challenging the current trend are known as leaning against the wind. Many researchers have found evidence for trend-resisting official interventions. ${ }^{19}$ Both types of official transactions have the potential to increase or decrease the dispersion of beliefs among market participants, depending on their expectations at or around the time when the intervention was planned.

It is also reasonable to imagine that Central Bank-originated trades are more likely to generate persistent effects on the domestic currency when reinforcing market sentiment, but that those effects are going to be more pronounced when information is revealed that alters investors' view about the exchange rate. It is then clearly of interest to establish if official interventions chasing or resisting a trend have a different impact on the process of price formation in the forex markets.

The third feature we focus on is market expectations. In the already mentioned paper by Naranjo and Nimalendran (2000), it is only the unex-

\footnotetext{
${ }^{18}$ Lewis (1995), for example, notes that during the period 1985-1987 the Federal Reserve, Bank of Japan, and the Bundesbank usually bought USD against Deutschemark and Yen if the dollar was weaker than the Louvre meeting's agreed level, and sold foreign currency reserves when the dollar was appreciating "too much".

${ }^{19}$ In several cases Central Banks were found buying dollars while the dollar was depreciating (Taylor (1982)), or buying dollars despite expectations of lower U.S. interest rates, i.e., inconsistently with current or future fundamentals (Lewis (1995), Kaminsky and Lewis (1996)). Edison (1993) reports strong empirical support for leaning against the wind interventions, but only weaker evidence of chasing the trend interventions attempting to correct misalignments in the foreign exchange market.
} 
pected component of Central Bank intervention to be related to the adverse selection component of the bid-ask spread in the forex market. In Pasquariello (2001b), uncertainty about the likelihood of arrival of orders from the Central Bank and the nature of its future actions make it more difficult for dealers to clear the market, and induce them to revise their posted quotes. According to these views, the expected component of official interventions should already be discounted in the exchange rate before those transactions actually occur, hence should not affect significantly prices and transaction costs. Consequently, only unexpected interventions should potentially induce the most sudden and radical revisions of market participants' beliefs, hence the biggest shocks in currency returns and volatility, in the existing degree of misinformation among investors and dealers, and in bid-offer spreads.

In this section we want to assess the relative significance of these considerations in explaining the impact of Central Bank interventions on currency returns, on the existing degree of information heterogeneity, on exchange rate volatility, and on various measures of market liquidity and transaction costs. We start by classifying SNB daily interventions based on whether they were big or small, on whether they were in the direction of or against an existing trend in the CHFUSD, or on whether the arrival of the Swiss Central Bank and the nature of its actions were expected by the market. Then, we reestimate Eqs. (2) and (3) to evaluate any contemporaneous and cumulated difference in the variables of interest in proximity of these new intervention types. We will also look at whether the decomposition of measured bid-ask spread shocks previously implemented in Section 4 is somehow altered by the proposed new groupings, by re-estimating Eqs. (12) and (13) as well.

We say that an aggregate intervention transaction in day $t, I_{t}$, is small (big) if its absolute magnitude is smaller than or equal to (greater than) the median absolute intervention size computed over the entire sample, $\$ 50$ million in our case. 57 of the 86 recorded official SNB interventions are so classified as small $\left(I_{\text {small }}\right)$ and 29 as big $\left(I_{\text {big }}\right)$. Many interventions are concentrated at the median size, hence $I_{\text {small }}$ s are more numerous than $I_{b i g} \mathrm{~s}$. About $80 \%$ of the actions in each of the two groups are dollar sales. We then define an intervention operation at day $t$ as chasing the trend (leaning against the wind) if its sign is equal to (the opposite of) the sign of the sum of cumulated daily exchange rate returns over the previous two trading days, i.e., if $\operatorname{sign}\left(I_{t}\right)=(\neq) \operatorname{sign}\left(r_{t-1}+r_{t-2}\right) \cdot{ }^{20}$ As a result, 22 interventions (of which

\footnotetext{
${ }^{20}$ This procedure was originally suggested by Payne and Vitale (2001). In their paper, interventions' signs are actually compared to exchange rate returns over the 24 hours preceding the event interval. Given the lower-frequency nature of our study, and to account for the possibility that the intervention may have been anticipated by the market, we decided to use a longer time-horizon, of two trading days before the intervention day.
} 
16 where CHF purchases) are classified as chasing the trend $\left(I_{\text {trend }}\right)$, while 64 (of which 12 where CHF sales) were leaning against the wind $\left(I_{\text {wind }}\right)$ according to our criterion. This evidence of more frequent interventions against an existing trend in the CHFUSD is consistent with previously mentioned empirical evidence for G3 Central Banks.

Finally, we want to classify the available intervention events as expected or unexpected by market participants at or around the time they occurred. To do so we use a parsimonious method that, without specifying a full-fledged structural model for how investors form their expectations about the actions of the monetary authority, allows us to use the information contained in the observed prices at which those official transactions were executed. In these prices in fact should those expectations have been discounted in an efficient market such as the forex market is usually deemed to be.

Hence, an intervention should be expected if it is transacted at a price that already incorporates all or most of the relevant information related to that action, i.e., at a price that is not "too distant" from the average price at which trades on the same side of the market could have been executed in proximity of when that Central Bank order arrived. Because the SNB reveals the nature of its trade (intervention versus customer transaction) only after the completion of the trade itself, we look at prices posted not only before but also following the event time. We do in fact need to evaluate the degree of market surprise not only regarding the timing of the transaction, its sign, and magnitude but also regarding the revelation about its nature by the Swiss monetary authority soon after it has been cleared.

To implement this model-free criterion, we first divide each trading day in our joint database of tick-by-tick validated quotes and intraday SNB transactions into a succession of five-minute segments stretching from 5 a.m. to 9 p.m. GMT. Then, we classify each day $t$ intervention as unexpected (expected) if the price at which the first intervention trade of day $t$ is executed, $S_{t}^{C B}$, is (not) statistically different from the mean ask quote (for a dollar purchase by the SNB) or from the mean bid quote (for a dollar sale by the SNB) posted over a 35 -minute interval $\left[t_{n, y-3}, t_{n, y+3}\right]$ made of the five-minute period $y$ that includes the recorded time of the transaction $t_{n, y}$, and of the three five-minute periods before and after the $y$-th period. We focus on the first intervention of the day because, according to Fischer and Zurlinden (1999), this is the only transaction leading to a significant move on the CHFUSD exchange rate, since the information acquired by one dealer about that first official trade by the SNB tends to spread swiftly to other market-makers (and into their posted quotes) and eventually to the market at large.

More specifically, if for example the first official dollar purchase of day $t$ 
occurs at time $t_{n, y}$, corresponding to the $y$-th five-minute interval of the day, the corresponding expectation indicator $E_{t}$ is computed as a $T$-statistic,

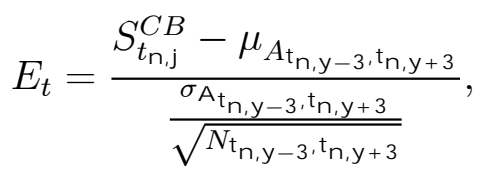

where $\mu_{A_{\mathrm{t}, \mathrm{y}-3, \mathrm{t}_{\mathrm{n}, \mathrm{y}+3}}}$ is the mean indicative ask price over the above-mentioned 35 -minute interval surrounding the event time, $\sigma_{A_{\mathrm{t}, y-3, t_{n, y+3}}}$ is the corresponding standard deviation, and $N_{t_{n, y-3}, t_{n, y+3}}$ is the number of filtered posted quotes in $\left[t_{n, y-3}, t_{n, y+3}\right] . \quad I_{t}$ is then going to be classified as unexpected (expected), $I_{u n \exp }\left(I_{\exp }\right)$, if the probability of the absolute value of a $t$ distributed statistic being as big or bigger than $\left|E_{t}\right|$ by chance is smaller than or equal to (bigger than) 1\%. When we implement this procedure for each of the 86 interventions in the sample, we find that only 13 of them were actually expected, at least according to Eq. (14). ${ }^{21}$ Eq. (14) allows us to evaluate the relevance of expectations about SNB actions in measuring their effects on market conditions without integrating a more complex modelling choice in the hypotheses we test throughout our statistical investigations.

\subsection{New action types: marginal and cumulated effects}

We start by estimating Eq. (2) to measure the impact of interventions of type $h=I_{\text {small }}, I_{\text {big }}, I_{\text {trend }}, I_{\text {wind }}, I_{\exp }$, and $I_{\text {un exp }}$ on each of contemporaneous variables of interest, $\boldsymbol{\theta}_{0}$, after controlling for weekday seasonalities and longterm trends, in Table 7 , and cumulated impact coefficients $\boldsymbol{b}_{-w}^{h}$ on the subset of them which displayed the most interesting dynamics in Figure $4, r_{t}, r_{t}^{2}, S_{t}$, and $d_{t}$ in Figure 6a to 6d, respectively. Again, in the special case in which $X_{t}=r_{t}$, we substitute the regressor $I_{t}(j, h)$ with the signed event dummy $I_{t}^{*}(j, h)$. The resulting adjusted $R^{2}$ s are very similar across different action types. Moreover, the concentration of transactions of the same sign in each of the new groups is consistent with the original sample $I$, i.e., roughly $20 \%$ of each (new and old) action type is made of CHF sales. Hence, a comparison of the estimated parameters $\boldsymbol{B}_{0}$ and $\boldsymbol{b}_{-w}^{h}$ across categories $h$ is a reasonable exercise.

Not surprisingly, interventions that are big in magnitude, leaning against the wind, or expected by the market induce the biggest marginal and ag-

\footnotetext{
${ }^{21}$ In particular, 3 of these 13 expected official interventions were USD purchases, while 58 of the remaining 73 unexpected SNB transactions were USD sales. These numbers either did not change or changed only marginally by expanding or tightening the window used to compute $E_{\mathrm{t}}$ or by altering the selected significance level.
} 
gregated impact on CHFUSD daily returns (of about $1 \%$ over 7 to 10 days surrounding the event), as evident from Figure 6a. We mentioned already the argument by Bhattacharya and Weller (1997) that bigger official transactions are usually more expensive for the monetary authority, thus represent the most credible signals of policy intentions or fundamentals to the market. Alternatively, according to Evans and Lyons (2001), large interventions may affect exchange rates because of imperfect asset substitutability at the market and dealer level. In our sample, however, the SNB tends to split evenly its intervention among traders for lots not larger than $\$ 10$ million each. Additionally, the mean number of intraday SNB transactions in dates when the intervention was big (11.5) is higher that the mean number of intraday SNB transactions registered when $h=I_{\text {small }}$ (6.30). This suggests that bigger interventions have more chances to be seen by more dealers, thus that in such circumstances the information regarding the interventions dissipates more fully, i.e., reaches more investors, hence making them more effective. Vice versa, along those lines, small and expected interventions are the least effective in moving cumulated exchange rate returns. The coefficient $\bigotimes_{0}$ for the absolute spread $S_{t}$ in Table 7 is positive and significant only when $h=I_{\text {big }}$. Nonetheless, this fact is hardly supportive of any explanation of bid-ask spread dynamics based on inventory in proximity of Central Bank interventions, as we have so far argued, when we consider that the SNB splits its large trades across several dealers. The above evidence may instead suggest that big interventions induce more misinformation among market participants, a possibility we explore in the analysis of spread shocks that follows in Section 5.2.

Interventions chasing the trend face fewer market frictions and obstacles, as they do not induce market participants to revise their beliefs about the currency, but rather reinforce those beliefs. Consistently with this fact, they also seem to only marginally affect the exchange rate, to be almost completely reabsorbed by the end of the first day following the event date, and to generate among the smallest shocks to volatility, as measured by both absolute returns in Table 7 and square returns in Figure 6b. Interestingly, $I_{\text {trend }}$ events are also typically anticipated by the market by at least two days before their occurrence, suggesting that uninformed dealers and investors are able to recognize levels of the currency around which trend-chasing interventions by the SNB become more likely. The impact of official SNB actions leaning against the wind, i.e., against current market sentiment, is instead very persistent, and is accompanied by greater shocks to exchange rate volatility.

It is when expected SNB actions hit the market that the CHFUSD exchange rate experienced the greatest fluctuations, cumulated excess volatility and duration were the highest, and dealers widened their spreads the most, 
contrary to the results of Naranjo and Nimalendran (2000), based on a structural model for the estimation of the anticipated component of Central Bank trades. A possible interpretation for this evidence can be found by looking at aggregated excess returns in the days preceding those events, in Figure 6a: extreme trends in the domestic currency appear to have led the market to anticipate the arrival of SNB-originated trades. Those trends, and the expected reaction by the Central Bank were also accompanied by greater uncertainty among dealers, as proxied by increasing spreads (in Figure 6c). In such circumstances, SNB interventions were only partially successful in resisting the directional move of the CHFUSD, which in fact appeared to reverse to pre-intervention levels few days after those official transactions were executed, as shown by the dynamics of $\varliminf_{-w}^{I_{\text {exp }}}$ for $r_{t}$ when $w<0$ in Figure 6a. Expected SNB interventions also failed to eliminate or reduce market volatility and transaction costs, for cumulated excess square returns (in Figure 6b) and spreads (in Figure 6c) actually increased following events of type $h=I_{\text {exp. }}$.

Both measures of liquidity shocks, $S_{t}$ and $d_{t}$, are very similar across classification criteria, with the exclusion of $I_{\exp }$. For most of the event types, in the days preceding the arrival of the Swiss monetary authority the intensity by which dealers post quotes on the FXFX page rarefies, to then recover in the days afterwards, consistently with what we had found for $h=I$. More generally, the evidence from Figure 6 and Table 7 does not reveal any significant difference in excess market liquidity, intensity of trading activity, and transaction costs ensuing from SNB actions, when these differences are based on most of the proposed event categories $h$, although our measures of intervention effectiveness and exchange rate volatility do vary, often substantially, depending on trade magnitude, market momentum, and dealers' expectations.

\subsection{New action types: spread shock decomposition}

It remains to verify whether the relative importance of information, liquidity, and volatility considerations in explaining observed shocks in transaction costs changes across the new intervention types. To do so, we estimate Eq. (12) and (13) for $h=I_{\text {small }}, I_{\text {big }}, I_{\text {trend }}, I_{\text {wind }}, I_{\text {exp }}$, and $I_{\text {un exp }}$ in Table 8, again using changes in $\left|r_{i}\right|$ and $\left|r_{i}(j)\right|$ to proxy for the shocks to exchange rate volatility $\Delta V_{i}$ and $\Delta V_{i}(j)$, respectively. The resulting estimated coefficients $\mathbb{R}_{0 i}$ to $\mathbf{S}_{5 i}$ are in most cases statistically significant, and in all cases their signs are as expected from the theory we presented in Section 4.

Big interventions, which Bhattacharya and Weller (1997) suggest being 
ex ante the most informative, and expected interventions, which should have surprised investors and market-makers the least, appear nonetheless to have induced the greatest amount of misinformation among market participants (i.e., the greatest $\mathbb{Q}_{0 i}$ ), consistently with evidence presented in the previous subsection. Aggregate changes in absolute spreads computed in proximity of interventions chasing the trend, ex ante the least informative because they are simply confirming existing investors' beliefs rather than challenging them, are instead independent from excess volatility induced by fundamental news. The coefficient ${ }_{2 i}$ for $h=I_{\text {trend }}$ is in fact not statistically different from zero. This is the case for expected interventions as well. This should again not be surprising, given that the market had probably already discounted any information content ensuing from those trades during the price formation process preceding their actual execution. When the SNB attempted to lean against the wind, the resulting degree of information heterogeneity $\mathbf{Q}_{0 i}$ was as low as for small (and less informative) official transactions and for $I_{\text {un exp }}$, suggesting that most investors and dealers agreed in the interpretation of the news generated by these types of actions.

Shocks to competition among dealers in proximity of SNB actions were a relevant factor in explaining the estimated $\Delta S_{i}>0$ (i.e., $\mathbb{1}_{4 i}$ is negative) just when interventions did not represent a surprise to investors or were above the median absolute size. The loss (gain) of immediacy displayed in Figure 6d, instead, always translated into greater (lower) spreads $\left(\$_{5 i}>0\right)$ unless when each day in the event interval $\left[t_{i}-8, t_{i}+8\right]$ is considered. Overall, in decomposing the observed changes in bid-ask spreads, the evidence we present shows that SNB actions did affect the degree of information heterogeneity among market participants and the relation between volatility, competition, market thinness, and spreads differently, depending on the nature of the event type $h$ or on the selected estimation window. Nonetheless, Table 8 also shows that all SNB interventions, whether big or small, toward or against market momentum, expected or unexpected, had a uniformly positive impact on market liquidity $\left(\$_{1 i}<0\right)$, which attenuated the increase in transaction costs borne by the population of investors at and around the time when those official trades were executed.

\section{Conclusions}

Are interventions in the foreign exchange market a source of information or just noise? Is there any cost borne by the population of investors stemming from Central Bank's attempts at managing the fluctuations of some key exchange rates? And, if so, why? These were the issues we raised at the 
beginning of this study. At this stage, we believe we can provide a comprehensive answer to such questions.

Our analysis suggests that official sterilized SNB interventions affected significantly different measures of exchange rate behavior, ex post volatility, market liquidity, and trading intensity both in the short and in the long-term. From extensive use of event-study methodology on the resulting joint dataset of indicative quotes and SNB transactions we find that official interventions, although representing only a small fraction of the average daily turnover in the CHFUSD market, had meaningful and persistent (albeit asymmetric, depending on their sign) effects on currency returns, stretching for several days after those transactions were executed, especially when big in size, leaning against the wind, or expected by the market. Interestingly, the market did not anticipate incoming interventions except when chasing the trend. On average, official dollar purchases followed a steady strengthening of the CHF, while official dollar sales frequently came as a reaction to a period of protracted weakness of the domestic currency.

Nonetheless, the Swiss monetary authority was much less successful in smoothing fluctuations of the currency or in reducing its variability. Ex post measures of exchange rate volatility in fact always surged in proximity of Central Bank interventions and stayed high for many days afterwards. Absolute and proportional spreads for the CHFUSD also increased or decreased in a (statistically and economically) significant fashion at or around the dates when Central Bank interventions were conducted by the SNB. In many cases, these effects too preceded the actual intervention event and were protracted in time. For example, we estimate that (annualized) transaction costs borne by investors and speculators increase on average by $\$ 100$ to over $\$ 400$ million in days when the SNB was selling USD/buying CHF, while instead decrease on average by $\$ 150$ to $\$ 640$ million when the Swiss monetary authority was engaged in USD purchases/CHF sales. Changes would be of even greater magnitude if computed on a cumulated basis. Because many of these effects were found to be statistically negligible for customer transactions, we conclude that the potential information content of SNB interventions must have played an important role in explaining their impact on the CHFUSD market.

Finally, decomposition of those spread shocks in proximity of SNB trades into shocks related to misinformation, liquidity, fundamental volatility, competition, and immediacy reveals that official interventions (especially if big in size or expected by the market) heightened heterogeneity of beliefs among market participants, impacted significantly trading immediacy and ex post exchange rate variation (unless if chasing the trend), and increased market liquidity and competition among dealers for the incoming orders. Many of these changes were costly, i.e., translated into higher transaction costs borne 
by the population of investors, even when the interventions were not effective in altering existing market momentum or, as it was very often the case, in stabilizing disorderly market conditions.

This paper offers many avenues for further research. For example, we showed here that official interventions have significant and long-lasting effects on bid-ask spreads and other daily measures of market liquidity. It may be of interest to investigate those dynamics over finer levels of aggregation using our database of intraday transactions by the Swiss monetary authority. In this study we also strongly emphasize the failure by the SNB to smooth existing currency fluctuations, which instead typically increase around the time when official interventions were recorded. Although the costs suffered by risk-averse investors and dealers in rebalancing their portfolios in response to enhanced market uncertainty are difficult to estimate, they must probably be relevant. Exploring the nature and direction of causality in the potential relation between estimated excess volatility and the Central Bank's attempts to manage the domestic currency or to curb profits from speculation, and, more generally, developing a clearer understanding of the process by which (ex ante) expected and (ex post) realized exchange rate volatility change in anticipation and in response to the actions of an active monetary authority are tasks that certainly deserve more attention and efforts.

We believe that our dataset offers an unparalleled opportunity for financial economists to study in a comprehensive manner the process by which dealers buy and sell foreign currency during a trading day when a non-profit maximizing player like the Central Bank is attempting to condition the process of price formation. We reserve these investigations for future work.

\section{References}

[1] Adams, D., Henderson, D. W. (1983). Definition and Measurement of Exchange Market Intervention. Staff Studies No. 126, Board of Governors of the Federal Reserve System.

[2] Amihud, Y., Mendelson, H. (1980). Dealership Market: Market-Making with Inventory. Journal of Financial Economics, 8, pp. 31-53.

[3] Andersen T., Bollerslev T. (1997). Heterogeneous Information Arrivals and Return Volatility Dynamics: Uncovering the Long-Run in High Frequency Returns. Journal of Finance, 52, pp. 975-1005.

[4] Andersen, T., Bollerslev, T., Diebold, F., Labys, P. (2002). Modeling and Forecasting Realized Volatility. Econometrica, forthcoming. 
[5] Bank for International Settlements (1999). Central Bank Survey of Foreign Exchange and Derivatives Market Activity 1998. Available at http://www.bis.org.

[6] Bessembinder, H. (1994). Bid-Ask Spreads in the Interbank Foreign Exchange Markets. Journal of Financial Economics, 35, pp. 317-348.

[7] Bhattacharya, U., Weller, P. (1997). The Advantage of Hiding One's Hand: Speculation and Central Bank Intervention in the Foreign Exchange Market. Journal of Monetary Economics, 39, pp. 251-277.

[8] Bollerslev, T., Domowitz, I. (1993). Trading Patterns and Prices in the Interbank Foreign Exchange Market. Journal of Finance, 48, pp. 14211443.

[9] Bollerslev, T., Melvin, M. (1994). Bid-Ask Spreads and Volatility in the Foreign Exchange Market: an Empirical Analysis. Journal of International Economics, 36, pp. 355-372.

[10] Branson, W. H. (1983). Macroeconomic Determinants of Real Exchange Risk. In Managing Foreign Exchange Risk, Ed. R. J. Herring, Cambridge University Press, Cambridge.

[11] Branson, W. H. (1984). A Model of Exchange Rate Determination with Policy Reaction: Evidence from Monthly Data. In Contemporary Macroeconomic Modelling, Eds. P. Malgrange and P. Muet, Basil Blackwell, Oxford, U.K.

[12] Chordia, T., Shivakumar, L., Subrahmanyam, A. (2000). The CrossSection of Daily Variation in Liquidity. Working Paper, London Business School.

[13] Cohen, K., Maier, S., Schwartz, R., Whitcomb, D. (1981). Transaction Costs, Order Placement Strategy, and Existence of the Bid-Ask Spread. Journal of Political Economy, 89, pp. 287-305.

[14] Copeland, T., Friedman, D. (1987). The Effect of Sequential Information Arrival on Asset Prices: An Experimental Study. Journal of Finance, 42, pp. 763-797.

[15] Dacorogna, M., Gençay, R., Müller, U., Olsen, R., Pictet, O. (2001). An Introduction to High-Frequency Finance. Academic Press, New York. 
[16] Dacorogna, M., Müller, U., Nagler, R., Olsen, R., Pictet, O. (1993). A Geographical Model for the Daily and Weekly Seasonal Volatility in the Foreign Exchange Market. Journal of International Money and Finance, 12, pp. 413-438.

[17] Dominguez, K. M. (1987). Exchange Rate Efficiency and the Behavior of International Asset Markets. Unpublished Ph.D. Thesis, Yale University.

[18] Dominguez, K. M. (1998). Central Bank Intervention and Exchange Rate Volatility. Journal of International Money and Finance, 17, pp. 161-190.

[19] Dominguez, K. M. (1999). The Market Microstructure of Central Bank Intervention. Working Paper 7337, NBER.

[20] Dominguez, K. M., Frankel, J. A. (1993). Does Foreign Exchange Intervention Work? Institute for International Economics, Washington.

[21] Edison, H. J. (1993). The Effectiveness of Central Bank Intervention: a Survey of Post-1982 Literature. Essays in International Finance, Princeton University Press, Princeton.

[22] Evans, M., Lyons, R. K. (2001). Portfolio Balance, Price Impact, and Secret Intervention. Working Paper 8356, NBER.

[23] Evans, M., Lyons, R. K. (2002). Order Flow and Exchange rate Dynamics. Journal of Political Economy, 110, pp. 170-180.

[24] Fedenia, M., Grammatikos, T. (1992). Option Trading and the Bid-Ask Spread of the Underlying Stocks. Journal of Business, 65, pp. 335-351.

[25] Fischer, A., Zurlinden, M. (1999). Exchange Rate Effects of Central Bank Interventions: an Analysis of Transaction Prices. Economic Journal, 109, pp. 662-676.

[26] Goodhart, C., Ito, T., Payne, R. (1996). One Day in June 1993: A Study of the Working of the Reuters 2000-2 Electronic Foreign Exchange Trading System. In The Microstructure of Foreign Exchange Markets, Eds. J. Frankel et al., NBER Conference Report, The University of Chicago Press, Chicago, pp. 107-179.

[27] Grossman, S., Miller, M. (1988). Liquidity and Market Structure. Journal of Finance, 43, pp. 617-633. 
[28] Guembel, A., Sussman, O. (2001). Optimal Exchange Rates: a MarketMicrostructure Approach. Working Paper, Said Business School, Oxford University.

[29] Hasbrouck, J. (1999). Security Bid/Ask Dynamics with Discreteness and Clustering: Simple Strategies for Modeling and Estimation. Journal of Financial Markets, 2, pp. 1-28.

[30] Hsieh, D., Kleidon, A., (1996). Bid-Ask Spreads in Foreign Exchange Markets: Implications for Models of Asymmetric Information. In The Microstructure of Foreign Exchange Markets, Eds. J. Frankel et al., NBER Conference Report, The University of Chicago Press, Chicago, pp. 41-65.

[31] Kaminsky, G. L., Lewis, K. (1996). Does Foreign Exchange Intervention Signal Future Monetary Policy? Journal of Monetary Economics, 37, pp. 285-312.

[32] Lewis, K. (1995). Occasional Intervention to Target Rates. American Economic Review, 85, pp. 691-715.

[33] Lyons, R. K. (1997). A Simultaneous Trade Model of the Foreign Exchange Hot Potato. Journal of International Economics, pp. 275-298.

[34] Lyons, R. K. (2001). The Microstructure Approach to Exchange Rates. MIT Press, Cambridge.

[35] Müller, U., Dacorogna, M., Olsen, R., Pictet, O., Schwarz, M., Morgenegg, C. (1990). Statistical Study of Foreign exchange Rates, Empirical Evidence of a Price Changing Scaling Law, and Intraday Analysis. Journal of Banking and Finance, 14, pp. 1189-1208.

[36] Mussa, M., (1981). The Role of Official Intervention. Group of Thirty Occasional Papers, No. 6.

[37] Naranjo, A., Nimalendran, M. (2000). Government Intervention and Adverse Selection Costs in Foreign Exchange Markets. Review of Financial Studies, 13, pp. 453-477.

[38] O'Hara, M. (1995). Market Microstructure Theory. Blackwell Publishers, Cambridge.

[39] Osterberg, W., Wetmore Humes, R. (1995). The Inaccuracy of Newspaper Reports of U.S. Foreign Exchange Intervention. Working Paper 9501, Federal Reserve Bank of Cleveland. 
[40] Pasquariello, P. (2001a). The Microstructure of Currency Markets: an Empirical Model of Intra-day Return and Bid-Ask Spread Behavior. Working Paper, Stern School of Business, New York University.

[41] Pasquariello, P. (2001b). Central Bank Intervention and the Intraday Process of Price Formation in the Currency Markets. Working Paper, Stern School of Business, New York University.

[42] Payne, R., Vitale, P. (2001). A Transaction Level Study of the Effects of Central Bank Intervention on Exchange Rates. Discussion Paper 3085, CEPR.

[43] Peiers, B. (1997). Informed Traders, Intervention and Price Leadership: a Deeper View of the Microstructure of the Foreign Exchange Market. Journal of Finance, 52, pp. 1589-1614.

[44] Saar, G. (2000a). Demand Uncertainty and the Information Content of the Order Flow. Working Paper, Stern School of Business, New York University.

[45] Saar, G. (2000b). Prices and Spreads in Sequential Markets with Information Imperfections. Working Paper, Stern School of Business, New York University.

[46] Sarno, L., Taylor, M. P. (2001). Official Intervention in the Foreign Exchange Market: Is it Effective, and if So, How Does it Work? Journal of Economic Literature, 39, pp. 839-868.

[47] Stein, J. (1987). Informational Externalities and Welfare-Reducing Speculation. Journal of Political Economy, 95, pp. 1123-1145.

[48] Stoll, H. R. (1978). The Supply of Dealer Services in Securities Markets. Journal of Finance, 33, pp. 1133-1151.

[49] Taylor, D. (1982). Official Intervention in the Foreign Exchange Market, or, Bet Against the Central Bank. Journal of Political Economy, 90, pp. 356-368.

[50] Vitale, P. (1999). Sterilised Foreign Exchange Intervention in the Foreign Exchange Market. Journal of International Economics, 49, pp. 245-267. 


\section{Table 1. Descriptive statistics on intraday SNB transactions on CHFUSD}

This table reports descriptive statistics for signed and unsigned intraday interventions $\left(I_{t_{\mathrm{i}}}\right)$ and customer transactions $\left(C_{t_{\mathrm{i}}}\right)$ executed by the SNB between April 17, 1986 and December 23, 1998. Transaction amounts are in millions of U.S. Dollars. A positive (negative) value for $I_{t_{\mathrm{i}}}$ or $C_{t_{\mathrm{i}}}$ represents a purchase (sale) of dollars. $N$ is the number of observations available in the sample for each item. $d$ is the number of dealers involved in the transaction for a given day. Skew is the coefficient of skewness, while Kurt is the excess kurtosis. The standard errors of these statistics in their corresponding asymptotic

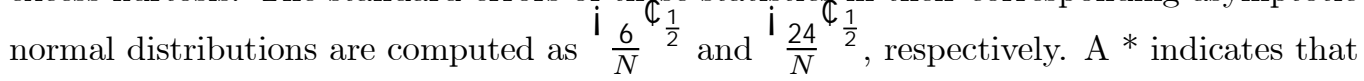
the statistic is significantly different from zero at the $10 \%$ level or less. In the case of $d$, a * indicates that the mean number of dealers involved in a SNB transaction over a given day $\left(\mu_{d}\right)$ is statistically different from 1 at the $10 \%$ significance level or less.

\begin{tabular}{|c|c|c|c|c|c|c|}
\hline & \multicolumn{6}{|c|}{ "Type of SNB transaction } \\
\hline & $I_{t_{\mathrm{i}}}$ & $I_{t_{\mathrm{i}}}>0$ & $I_{t_{\mathrm{i}}}<0$ & $C_{t_{\mathrm{i}}}$ & $C_{t_{\mathrm{i}}}>0$ & $C_{t_{\mathrm{i}}}<0$ \\
\hline $\mathrm{N}$ & 709 & 243 & 466 & 555 & 533 & 22 \\
\hline Mean & -3.29 & 8.40 & -9.39 & 16.26 & 17.30 & -8.96 \\
\hline Median & -5 & 10 & -10 & 10 & 10 & -10 \\
\hline Stdev & 10.41 & 3.23 & 7.14 & 23.03 & 22.90 & 3.58 \\
\hline Min & -100 & 5 & -100 & -18 & 0.7 & -18 \\
\hline Max & 35 & 35 & -5 & 200 & 200 & -1 \\
\hline Skew & $-1.40^{*}$ & $2.72^{*}$ & $-6.35^{*}$ & $3.98^{*}$ & $4.13^{*}$ & 0.19 \\
\hline Kurt & $11.45^{*}$ & $20.19^{*}$ & $63.05^{*}$ & $20.82^{*}$ & $21.54^{*}$ & 1.23 \\
\hline$\mu_{d}$ & $6.95^{*}$ & $7.15^{*}$ & $6.85^{*}$ & $1.70^{*}$ & $1.70^{*}$ & 1.83 \\
\hline$\sigma_{d}$ & 5.31 & 4.89 & 5.55 & 1.39 & 1.41 & 0.72 \\
\hline $\operatorname{Min} d$ & 1 & 1 & 1 & 1 & 1 & 1 \\
\hline $\operatorname{Max} d$ & 36 & 21 & 36 & 10 & 10 & 3 \\
\hline
\end{tabular}


Table 2. Descriptive statistics on daily SNB transactions on CHFUSD

This table reports descriptive statistics for aggregated daily interventions $\left(I_{t}\right)$ and customer transactions $\left(C_{t}\right)$ executed by the SNB between April 17, 1986 and December 23, 1998. Transaction amounts are in millions of U.S. Dollars. A positive (negative) value for $I_{t}$ or $C_{t}$ represents a purchase (sale) of dollars.

\begin{tabular}{|c|c|c|c|c|c|c|}
\hline & \multicolumn{6}{|c|}{ Type of SNB transaction } \\
\hline & $I_{t}$ & $I_{t}>0$ & $I_{t}<0$ & $C_{t}$ & $C_{t}>0$ & $C_{t}<0$ \\
\hline $\mathrm{N}$ & 102 & 34 & 68 & 326 & 314 & 12 \\
\hline Mean & -22.89 & 60 & -64.34 & 27.68 & 29.36 & -16.42 \\
\hline Median & -25 & 50 & -50 & 15 & 15 & -20 \\
\hline Stdev & 93.76 & 34.82 & 86.17 & 56.25 & 56.62 & 8.16 \\
\hline \multicolumn{7}{|c|}{ Monday } \\
\hline $\mathrm{N}$ & 18 & 6 & 12 & 60 & 57 & 3 \\
\hline Mean & -7.5 & 62.5 & -42.5 & 37.24 & 39.84 & -12 \\
\hline Median & -22.5 & 55 & -40 & 13.05 & 15 & -5 \\
\hline Stdev & 57.42 & 30.29 & 25.89 & 105.12 & 107.22 & 15.72 \\
\hline \multicolumn{7}{|c|}{ Tuesday } \\
\hline $\mathrm{N}$ & 23 & 11 & 12 & 53 & 52 & 1 \\
\hline Mean & 3.70 & 57.73 & -45.83 & 32.20 & 33.20 & -20 \\
\hline Median & -20 & 50 & -30 & 15 & 15 & -20 \\
\hline Stdev & 61.11 & 34.89 & 27.70 & 58.99 & 59.11 & n.a. \\
\hline \multicolumn{7}{|c|}{ Wednesday } \\
\hline $\mathrm{N}$ & 18 & 6 & 12 & 67 & 65 & 2 \\
\hline Mean & -41.94 & 62.5 & -94.17 & 23.52 & 24.70 & -15 \\
\hline Median & -25 & 50 & -32.5 & 15 & 15 & -15 \\
\hline Stdev & 144.22 & 30.62 & 150.98 & 28.80 & 28.40 & 7.07 \\
\hline \multicolumn{7}{|c|}{ Thursday } \\
\hline $\mathrm{N}$ & 15 & 5 & 10 & 68 & 65 & 3 \\
\hline Mean & -19.67 & 69 & -64 & 24.80 & 26.89 & -20.33 \\
\hline Median & -50 & 55 & -62.5 & 16 & 17 & -20 \\
\hline Stdev & 69.75 & 35.78 & 21.19 & 30.35 & 29.40 & 0.57 \\
\hline \multicolumn{7}{|c|}{ Friday } \\
\hline $\mathrm{N}$ & 28 & 6 & 22 & 78 & 75 & 3 \\
\hline Mean & -44.10 & 51.67 & -70.22 & 23.32 & 24.92 & -16.67 \\
\hline Median & -27.5 & 35 & -40 & 14 & 15 & -20 \\
\hline Stdev & 103.31 & 49.97 & 98.97 & 31.83 & 31.40 & 5.78 \\
\hline
\end{tabular}




\section{Table 3. Descriptive statistics on CHFUSD grouped variables}

This table reports summary statistics (defined in the notes to Table 1) for $r_{t},\left|r_{t}\right|$, $r_{t}^{2}, S_{t}, s_{t}, d_{t}$, and $f_{t}$ computed over the interval January 2, 1986 - December 31, 1998. $r_{t}$ is the cumulative daily return over day $t$. The cumulative daily absolute return, $\left|r_{t}\right|$, and square return, $r_{t}^{2}$, are proxies for daily exchange rate volatility. $S_{t}$ is the average bid-ask spread (in units of basis points) over day $t$, while $s_{t}$ is the average logarithmic bid-ask spread over day $t$. Finally, the duration variable $d_{t}$ is the average length of time (in seconds) between consecutive quotes posted on the Reuters terminals over day $t$, while the frequency variable $f_{t}$ is the number of posted quotes over day $t . \boldsymbol{p}_{h}$ is the first-order estimated autocorrelation. $L B(5)$ is the Ljung-Box test for up to the fifth-order serial correlation. $\mathrm{A} *$ indicates that the statistic is not different from zero at any conventional significance level.

\begin{tabular}{|c|c|c|c|c|c|c|c|}
\hline & $\mathrm{N}$ & Mean & Stdev & Skew & Kurt & $p_{1}$ & $L B(5)$ \\
\hline$r_{t}$ & 3,352 & $-0.0079 \%^{*}$ & $0.7338 \%$ & -0.11 & 2.23 & $0.024^{*}$ & 14.85 \\
\hline$\left|r_{t}\right|$ & 3,352 & 0.4216 & 0.2175 & 1.01 & 1.73 & 0.527 & 1,101 \\
\hline$r_{t}^{2}$ & 3,352 & 0.00020 & 0.00014 & 1.99 & 7.56 & 0.472 & 946.8 \\
\hline$S_{t}$ & 3,352 & 9.4391 & 1.2466 & 5.17 & 44.31 & 0.473 & 948 \\
\hline$s_{t}$ & 3,352 & $0.0659 \%$ & $0.0077 \%$ & 2.35 & 14.40 & 0.503 & 1,024 \\
\hline$d_{t}$ & 3,352 & 56.66 & 275.40 & 20.78 & 485.26 & 0.084 & 28.02 \\
\hline$f_{t}$ & 3,352 & 1873.1 & 868.9 & 0.90 & 0.88 & 0.541 & 1,158 \\
\hline
\end{tabular}


Table 4. Impact regression estimates

This table reports GMM estimates for the parameter $\delta_{0}$ in the regression

$$
X_{t}=\alpha+{ }_{l=1}^{\mathrm{P} 2} \gamma_{l} X_{t-l}+\delta_{0} I_{t}(0, h)+{ }_{i=1}^{\mathrm{P}} \psi_{i} D_{t}(i)+{ }_{k=1986}^{1997} \vartheta_{k} Y_{t}(k)+\varepsilon_{t},
$$

described in Section 3 (Eq.(2)), for each of the variables of interest $X_{t}$, from $r_{t}$ to $f_{t}$, defined in the notes to Table 3 . B $_{0}$ measures the impact of event $h$, for $h=I, I \gtrless 0$, $C, C \gtrless 0$, or $I \& C$, on $X$, after controlling for weekday seasonalities (with day-of-theweek dummies $D_{t}(i)$ ) and long-term trends (with year dummies $Y_{t}(k)$ ). $I_{t}(0, h)$ is an unsigned event dummy equal to 1 if the transaction of type $h$ occurred in day $t$, and to zero otherwise. T-statistics for $B_{0}$ are computed using Newey-West standard errors. $R_{a}^{2}$ is the adjusted $R^{2}$. A ^ indicates that we replaced $I_{t}(0, h)$ with the signed event dummy $I_{t}^{*}(0, h)$ equal to $1(-1)$ if a USD purchase (sale) of type $h$ occurred in day $t$, and to zero otherwise. A* indicates that the t-statistic is significant at the $10 \%$ level or less. Estimates for the other coefficients in Eq. (2) are available from the author on request.

\begin{tabular}{c|ccccccc}
\hline \hline & \multicolumn{7}{c}{ 8 $_{0}$ for different event types $h$} \\
\cline { 2 - 8 } \multicolumn{1}{c}{} & $I$ & $I>0$ & $I<0$ & $C$ & $C>0$ & $C<0$ & $I \& C$ \\
\hline$r_{t}$ & $0.089 \%$ & $0.139 \%$ & $-0.074 \%$ & $-0.081 \%$ & $-0.097 \%$ & $-0.252 \%$ & $0.058 \%$ \\
T-stat & 0.86 & 0.54 & -0.69 & $-1.93^{*}$ & $-2.36^{*}$ & -1.07 & 0.19 \\
$R_{a}^{2}$ & $0.66 \%^{\wedge}$ & $0.65 \%$ & $0.65 \%$ & $0.72 \%^{\wedge}$ & $0.76 \%$ & $0.67 \%$ & $0.63 \%$ \\
\hline$\left|r_{t}\right|$ & 0.0489 & 0.0934 & 0.0358 & -0.0016 & -0.0028 & 0.0246 & 0.0434 \\
T-stat & $5.20^{*}$ & $3.17^{*}$ & $4.51^{*}$ & -0.25 & -0.44 & 0.87 & $2.16^{*}$ \\
$R_{a}^{2}$ & $73.13 \%$ & $73.10 \%$ & $73.06 \%$ & $73.01 \%$ & $73.01 \%$ & $73.16 \%$ & $73.03 \%$ \\
\hline$r_{t}^{2}$ & 0.00005 & 0.00009 & 0.00003 & $3.5 \mathrm{E}-6$ & $3.3 \mathrm{E}-6$ & $8.5 \mathrm{E}-6$ & 0.00006 \\
T-stat & $4.94^{*}$ & $2.96^{*}$ & $4.46^{*}$ & 0.64 & 0.58 & 0.47 & $2.44^{*}$ \\
$R_{a}^{2}$ & $64.92 \%$ & $64.89 \%$ & $64.78 \%$ & $64.69 \%$ & $64.69 \%$ & $64.88 \%$ & $64.77 \%$ \\
\hline$S_{t}$ & 0.0726 & -0.2545 & 0.1666 & 0.0462 & 0.0577 & -0.2066 & 0.7860 \\
T-stat & 0.88 & -1.01 & $2.36^{*}$ & 0.89 & 1.09 & $-2.45 *$ & 1.53 \\
$R_{a}^{2}$ & $65.39 \%$ & $65.40 \%$ & $65.41 \%$ & $65.39 \%$ & $65.40 \%$ & $65.39 \%$ & $65.57 \%$ \\
\hline$s_{t}$ & $6.4 \mathrm{E}-5 \%$ & $-0.002 \%$ & $0.0005 \%$ & $0.0007 \%$ & $0.0008 \%$ & $-0.0008 \%$ & $0.0073 \%$ \\
T-stat & 0.10 & -0.63 & 1.09 & $2.31^{*}$ & $2.46^{*}$ & $-2.25 *$ & $1.78^{*}$ \\
$R_{a}^{2}$ & $64.47 \%$ & $64.49 \%$ & $64.48 \%$ & $64.54 \%$ & $64.55 \%$ & $64.48 \%$ & $64.89 \%$ \\
\hline$d_{t}$ & -30.68 & -26.02 & -31.90 & -18.17 & -17.45 & -31.85 & -48.55 \\
T-stat & $-2.39^{*}$ & $-2.36^{*}$ & $-2.01^{*}$ & $-2.32^{*}$ & $-2.20 *$ & -1.63 & -1.11 \\
$R_{a}^{2}$ & $1.00 \%$ & $0.98 \%$ & $1.00 \%$ & $1.01 \%$ & $1.00 \%$ & $0.98 \%$ & $0.99 \%$ \\
\hline$f_{t}$ & 104.9 & 134.1 & 95.94 & -19.21 & -27.67 & 164.4 & 60.31 \\
T-stat & $3.04^{*}$ & $2.38^{*}$ & $2.33^{*}$ & -0.89 & -1.26 & $1.93^{*}$ & 0.86 \\
$R_{a}^{2}$ & $79.44 \%$ & $79.42 \%$ & $79.43 \%$ & $79.41 \%$ & $79.41 \%$ & $79.42 \%$ & $79.41 \%$ \\
\hline \hline
\end{tabular}




\section{Table 5. The impact of SNB-originated trades on transaction costs}

In this table we compute, as in Naranjo and Nimalendran (2000), the average annualized increase or decrease in transaction costs (in millions of U.S. Dollars) induced by SNB interventions for different estimates of daily CHFUSD turnover (in millions of U.S. Dollars). Because we do not know how much of that turnover is due to sales or purchases of USD, each of those amounts is divided in half and multiplied by the estimated change in the daily absolute spread $S_{t}$ (in units of basis points) from Table 4 , $\boldsymbol{\otimes}_{0}$, when $h=I>0$ and $h=I<0$, for each million of USD bought or sold. The resulting values are then multiplied by 252 (trading days) to provide annualized estimates. A * indicates that the variable is significant at the $10 \%$ level or less.

\begin{tabular}{c|cc|cc}
\hline \hline \multicolumn{1}{c}{ Turnover } & $\oint_{0}$ for $I>0$ & \multicolumn{1}{c}{ Annual Cost/Gain } & $\bigotimes_{0}$ for $I<0$ & Annual Cost/Gain \\
\hline$\$ 50,000$ & -0.254 & $-\$ 160.27$ & $0.167^{*}$ & $\$ 104.96$ \\
$\$ 75,000$ & -0.254 & $-\$ 240.41$ & $0.167^{*}$ & $\$ 157.44$ \\
$\$ 100,000$ & -0.254 & $-\$ 320.54$ & $0.167^{*}$ & $\$ 209.92$ \\
$\$ 125,000$ & -0.254 & $-\$ 400.68$ & $0.167^{*}$ & $\$ 262.40$ \\
$\$ 150,000$ & -0.254 & $-\$ 480.82$ & $0.167^{*}$ & $\$ 314.87$ \\
$\$ 175,000$ & -0.254 & $-\$ 560.95$ & $0.167^{*}$ & $\$ 367.35$ \\
$\$ 200,000$ & -0.254 & $-\$ 641.09$ & $0.167^{*}$ & $\$ 419.83$ \\
\hline \hline
\end{tabular}


Table 6a. Event shock decomposition: aggregated spreads $\bar{S}_{i}$

This table reports GMM estimates for the parameters $\lambda_{0 i}$ to $\lambda_{5 i}$ in the regression

$$
\Delta S_{i}=\lambda_{0 i}+\lambda_{1 i} \bar{S}_{i}^{b}+\lambda_{2 i} \Delta V_{i}+\lambda_{3 i}\left(\Delta V_{i}\right)^{2}+\lambda_{4 i} \Delta f_{i}+\lambda_{5 i} \Delta d_{i}+\varepsilon_{i},
$$

described in Section 4.1 (Eq.(12)), where $\Delta S_{i}$ is the aggregate shock on the absolute spread computed over the entire interval $\left[t_{i}-8, t_{i}+8\right]$ surrounding the time $t_{i}$ when an event $h$ occurred, for $h=I, I \gtrless 0, I \& C$, or $C$, and where volatility shocks $\Delta V_{i}$ are measured by changes in $\left|r_{i}\right|$. T-statistics are computed using Newey-West standard errors. $R_{a}^{2}$ is the adjusted $R^{2}$. DW is the Durbin-Watson statistic for residuals' autocorrelation, and $B P$ is the Breusch-Pagan chi-square statistic for residuals' heteroskedasticity. A * indicates that the statistic or parameter is significant at the $10 \%$ level or less.

\begin{tabular}{|c|c|c|c|c|c|c|c|c|c|c|}
\hline & $Q_{0 i}$ & $\mathrm{Q}_{1 i}$ & $\Phi_{2 i}$ & $Q_{3 i}$ & $\mathbb{1}_{4 i}$ & $Q_{5 i}$ & $R_{a}^{2}$ & $D W$ & $B P$ & $N$ \\
\hline \multicolumn{11}{|c|}{$I$} \\
\hline$\Delta S_{i}$ & $8.600^{*}$ & $-0.901^{*}$ & $2.691^{*}$ & $-17.879^{*}$ & & & $31.51 \%$ & $0.50^{*}$ & $8.33^{*}$ & 86 \\
\hline$\Delta S_{i}$ & $5.186^{*}$ & $-0.546^{*}$ & $4.949^{*}$ & $-9.456^{*}$ & -0.0007 & $0.0035^{*}$ & $77.81 \%$ & $0.75^{*}$ & 1.75 & 86 \\
\hline \multicolumn{11}{|c|}{$I>0$} \\
\hline$\Delta S_{i}$ & 4.426 & -0.411 & $2.198^{*}$ & -14.459 & & & $-0.33 \%$ & $0.76^{*}$ & 5.78 & 18 \\
\hline$\Delta S_{i}$ & 1.570 & -0.164 & 1.145 & -0.611 & 0.0007 & $0.0046^{*}$ & $88.00 \%$ & $1.51^{*}$ & 5.49 & 18 \\
\hline \multicolumn{11}{|c|}{$I<0$} \\
\hline$\overline{\Delta S_{i}}$ & $14.930^{*}$ & $-1.596^{*}$ & $3.603^{*}$ & -20.789 & & & $72.14 \%$ & $0.99^{*}$ & 1.77 & 68 \\
\hline$\Delta S_{i}$ & $10.218^{*}$ & $-1.092^{*}$ & $5.198^{*}$ & -10.881 & -0.0005 & $0.0025^{*}$ & $84.35 \%$ & $1.02^{*}$ & 3.43 & 68 \\
\hline \multicolumn{11}{|c|}{$I \& C$} \\
\hline$\overline{\Delta S_{i}}$ & 4.534 & -0.455 & $22.485^{*}$ & $-123.61^{*}$ & & & $36.30 \%$ & $0.84^{*}$ & 5.90 & 16 \\
\hline$\Delta S_{i}$ & $2.385^{*}$ & $-0.253^{*}$ & $16.428^{*}$ & $-42.358^{*}$ & $-0.0029^{*}$ & $0.0015^{*}$ & $96.33 \%$ & $1.55^{*}$ & 6.53 & 16 \\
\hline \multicolumn{11}{|c|}{$C$} \\
\hline$\Delta S_{i}$ & $4.154^{*}$ & $-0.444^{*}$ & 0.741 & -1.176 & & & $47.79 \%$ & $0.29^{*}$ & $15.43^{*}$ & 310 \\
\hline$\Delta S_{i}$ & $3.048^{*}$ & $-0.340^{*}$ & $6.383^{*}$ & -3.892 & $-0.0018^{*}$ & $0.0017^{*}$ & $59.29 \%$ & $0.30^{*}$ & $37.91^{*}$ & 310 \\
\hline
\end{tabular}


Table 6b. Event shock decomposition: single spreads $S_{i}(j)$

This table reports GMM estimates for the parameters $\lambda_{0 i}$ to $\lambda_{5 i}$ in the regression

$\Delta S_{i}(j)=\lambda_{0 i}+\lambda_{1 i} \bar{S}_{i}^{b}+\lambda_{2 i} \Delta V_{i}(j)+\lambda_{3 i}\left(\Delta V_{i}(j)\right)^{2}+\lambda_{4 i} \Delta f_{i}(j)+\lambda_{5 i} \Delta f_{i}(j)+\varepsilon_{i}$,

described in Section 4.1 (Eq.(13)), where $\Delta S_{i}(j)$ is the shock on the absolute spread over each of the days $t_{i}+j$ surrounding the time $t_{i}$ when an event $h$ occurred, for $j \in[-8,8]$ and $h=I, I \gtrless 0, I \& C$, or $C$, and where volatility shocks $\Delta V_{i}(j)$ are measured by changes in $\left|r_{i}(j)\right|$. T-statistics are computed using Newey-West standard errors. $R_{a}^{2}$ is the adjusted $R^{2}$. The statistics are defined in the notes to Table $6 \mathrm{a} . \mathrm{A} *$ indicates that the statistic or parameter is significant at the $10 \%$ level or less.

\begin{tabular}{|c|c|c|c|c|c|c|c|c|c|c|}
\hline & $\Phi_{0 i}$ & $\mathbb{1}_{1 i}$ & $\$ \Phi_{2 i}$ & $\Phi_{3 i}$ & 14i & $\Phi_{5 i}$ & $R_{a}^{2}$ & $\overline{D W}$ & $B P$ & $N$ \\
\hline \multicolumn{11}{|c|}{$I$} \\
\hline$\Delta S_{i}(j)$ & $8.004^{*}$ & $-0.839^{*}$ & $-1.665^{*}$ & $5.218^{*}$ & & & $15.59 \%$ & $0.91^{*}$ & $81.78^{*}$ & $\overline{1,462}$ \\
\hline$\Delta S_{i}(j)$ & $5.640^{*}$ & $-0.577^{*}$ & $5.723^{*}$ & -1.203 & $-0.0021^{*}$ & 0.0002 & $39.21 \%$ & $1.24^{*}$ & $228.9^{*}$ & 1,462 \\
\hline \multicolumn{11}{|c|}{$I>0$} \\
\hline$\Delta S_{i}(j)$ & $3.105^{*}$ & $-0.279^{*}$ & 0.091 & -0.378 & & & $0.82 \%$ & $1.20^{*}$ & 2.76 & 306 \\
\hline$\Delta S_{i}(j)$ & 1.342 & -0.116 & $8.113^{*}$ & $-4.224^{*}$ & $-0.0035^{*}$ & $-0.0003^{*}$ & $37.08 \%$ & $1.38^{*}$ & $55.40^{*}$ & 306 \\
\hline \multicolumn{11}{|c|}{$I<0$} \\
\hline$\Delta S_{i}(j)$ & $14.903^{*}$ & $-1.607^{*}$ & $-2.071^{*}$ & $19.576^{*}$ & & & $45.75 \%$ & $1.07^{*}$ & $63.75^{*}$ & 1,156 \\
\hline$\Delta S_{i}(j)$ & $11.426^{*}$ & $-1.222^{*}$ & $3.365^{*}$ & $12.699^{*}$ & $-0.0014^{*}$ & 0.0002 & $54.18 \%$ & $1.16^{*}$ & $169.1^{*}$ & 1,156 \\
\hline \multicolumn{11}{|c|}{$I \& C$} \\
\hline$\Delta S_{i}(j)$ & 1.297 & -0.073 & -0.384 & -1.768 & & & $-0.46 \%$ & $1.05^{*}$ & 2.43 & 272 \\
\hline$\Delta S_{i}(j)$ & $3.081^{*}$ & $-0.314^{*}$ & $15.586^{*}$ & $-11.692^{*}$ & $-0.0046^{*}$ & $-0.0002^{*}$ & $47.55 \%$ & $1.37^{*}$ & $45.37^{*}$ & 272 \\
\hline \multicolumn{11}{|c|}{$C$} \\
\hline$\Delta S_{i}(j)$ & $4.109^{*}$ & $-0.440^{*}$ & 0.248 & 0.197 & & & $31.07 \%$ & $0.63^{*}$ & $154.8^{*}$ & 5,270 \\
\hline$\Delta S_{i}(j)$ & $4.014^{*}$ & $-0.435^{*}$ & $7.083^{*}$ & $-3.766^{*}$ & $-0.0020^{*}$ & $0.0002^{*}$ & $42.83 \%$ & $0.69^{*}$ & $486.5^{*}$ & 5,270 \\
\hline
\end{tabular}


Table 7. Additional impact regression estimates

This table reports standard GMM estimates for the parameter $\delta_{0}$ in the regression

$$
X_{t}=\alpha+{ }_{l=1}^{\mathrm{P}} \gamma_{l} X_{t-l}+\delta_{0} I_{t}(0, h)+{ }_{i=1}^{\mathrm{P}} \psi_{i} D_{t}(i)+{ }_{k=1986}^{1997} \vartheta_{k} Y_{t}(k)+\varepsilon_{t},
$$

described in Section 3 (Eq.(2)), for each of the variables of interest $X_{t}$, from $r_{t}$ to $f_{t}$, defined in the notes to Table 3. $B_{0}$ measures the impact of the events $h=I, I_{\text {small }}$,

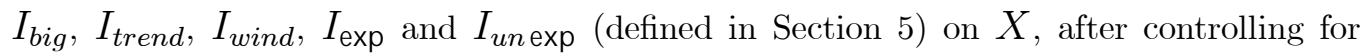
weekday seasonalities (with day-of-the-week dummies $D_{t}(i)$ ) and long-term trends (with year dummies $\left.Y_{t}(k)\right)$. The unsigned event dummy $I_{t}(0, h)$ and the signed event dummy $I_{t}^{*}(0, h)$ have been described in the notes to Table 4 . T-statistics for $\boldsymbol{B}_{0}$ are computed using Newey-West standard errors. $R_{a}^{2}$ is the adjusted $R^{2}$. A ^ indicates that we replaced $I_{t}(0, h)$ with $I_{t}^{*}(0, h)$ for the event type $h . \mathrm{A}^{*}$ indicates that the statistic is significant at the $10 \%$ level or less. Estimates for the other coefficients in Eq. (2) are available from the author on request.

\begin{tabular}{c|ccccccc}
\hline \hline & \multicolumn{7}{c}{ O $_{0}$ for different event types $h$} \\
\cline { 2 - 8 } \multicolumn{1}{c}{} & $I$ & $I_{\text {small }}$ & $I_{\text {big }}$ & $I_{\text {trend }}$ & $I_{\text {wind }}$ & $I_{\exp }$ & $I_{\text {un exp }}$ \\
\hline$r_{t}$ & $-0.089 \%$ & $0.144 \%$ & $-0.026 \%$ & $0.221 \%$ & $0.037 \%$ & $0.495 \%$ & $0.009 \%$ \\
T-stat & -0.86 & 1.14 & -0.18 & 1.08 & 0.33 & 1.60 & 0.09 \\
$R_{a}^{2}$ & $0.66 \%^{\wedge}$ & $0.69 \%^{\wedge}$ & $0.63 \%^{\wedge}$ & $0.69 \%^{\wedge}$ & $0.63 \%^{\wedge}$ & $0.80 \%^{\wedge}$ & $0.63 \%^{\wedge}$ \\
\hline$\left|r_{t}\right|$ & 0.0489 & 0.0482 & 0.0447 & 0.0224 & 0.0562 & 0.0417 & 0.0492 \\
T-stat & $5.20^{*}$ & $5.26^{*}$ & $2.12^{*}$ & 1.55 & $4.91^{*}$ & $2.63^{*}$ & $4.63^{*}$ \\
$R_{a}^{2}$ & $73.13 \%$ & $73.08 \%$ & $73.04 \%$ & $73.01 \%$ & $73.13 \%$ & $73.02 \%$ & $73.11 \%$ \\
\hline$r_{t}^{2}$ & 0.00005 & 0.00004 & 0.00006 & 0.00003 & 0.00005 & 0.00005 & 0.00004 \\
T-stat & $4.94^{*}$ & $4.04^{*}$ & $3.18^{*}$ & $2.30^{*}$ & $4.40^{*}$ & $3.85^{*}$ & $4.09^{*}$ \\
$R_{a}^{2}$ & $64.92 \%$ & $64.78 \%$ & $64.83 \%$ & $64.71 \%$ & $64.89 \%$ & $64.73 \%$ & $64.87 \%$ \\
\hline$S_{t}$ & 0.0726 & -0.0370 & 0.2698 & 0.0205 & 0.0879 & 0.0105 & 0.0829 \\
T-stat & 0.88 & -0.37 & $1.74^{*}$ & 0.25 & 0.89 & 0.08 & 0.97 \\
$R_{a}^{2}$ & $65.39 \%$ & $65.38 \%$ & $65.42 \%$ & $65.38 \%$ & $65.39 \%$ & $65.38 \%$ & $65.39 \%$ \\
\hline$s_{t}$ & $6.4 \mathrm{E}-5 \%$ & $-0.0009 \%$ & $0.0018 \%$ & $-0.0005 \%$ & $0.0002 \%$ & $-0.0005 \%$ & $0.0002 \%$ \\
T-stat & 0.10 & -1.05 & $1.75^{*}$ & -0.74 & 0.34 & -0.49 & 0.28 \\
$R_{a}^{2}$ & $64.47 \%$ & $64.49 \%$ & $64.52 \%$ & $64.48 \%$ & $64.48 \%$ & $64.48 \%$ & $64.47 \%$ \\
\hline$d_{t}$ & -30.68 & -31.68 & -25.41 & -22.12 & -32.34 & -22.40 & -31.61 \\
T-stat & $-2.39^{*}$ & $-2.31^{*}$ & $-2.38^{*}$ & $-2.00^{*}$ & $-2.45^{*}$ & $-2.54^{*}$ & $-2.30^{*}$ \\
$R_{a}^{2}$ & $1.00 \%$ & $0.99 \%$ & $0.98 \%$ & $0.98 \%$ & $1.00 \%$ & $0.97 \%$ & $1.00 \%$ \\
\hline$f_{t}$ & 104.9 & 167.7 & -24.84 & 4.53 & 136.2 & 17.66 & 119.3 \\
T-stat & $3.04^{*}$ & $4.19^{*}$ & -0.39 & 0.07 & $3.26^{*}$ & 0.17 & $3.43^{*}$ \\
$R_{a}^{2}$ & $79.44 \%$ & $79.46 \%$ & $79.41 \%$ & $79.41 \%$ & $79.45 \%$ & $79.41 \%$ & $79.44 \%$ \\
\hline \hline & & & & & & & \\
\hline
\end{tabular}


Table 8. Additional event shock decomposition

This table reports GMM estimates for the parameters $\lambda_{0 i}$ to $\lambda_{5 i}$ in the regression

$$
\Delta S_{i}=\lambda_{0 i}+\lambda_{1 i} \bar{S}_{i}^{b}+\lambda_{2 i} \Delta V_{i}+\lambda_{3 i}\left(\Delta V_{i}\right)^{2}+\lambda_{4 i} \Delta f_{i}+\lambda_{5 i} \Delta d_{i}+\varepsilon_{i},
$$

described in Section 4.1 (Eq. (11)), with $\Delta S_{i}$ being the aggregate shock on the absolute spread computed over the entire interval $\left[t_{i}-8, t_{i}+8\right]$ surrounding the time $t_{i}$ when an event of type $h$ occurred, and in the regression

$\Delta S_{i}(j)=\lambda_{0 i}+\lambda_{1 i} \bar{S}_{i}^{b}+\lambda_{2 i} \Delta V_{i}(j)+\lambda_{3 i}\left(\Delta V_{i}(j)\right)^{2}+\lambda_{4 i} \Delta f_{i}(j)+\lambda_{5 i} \Delta d_{i}(j)+\varepsilon_{i}$,

described in Section 4.1 (Eq. (13)), with $\Delta S_{i}(j)$ being the shock on the absolute spread over each of the days $t_{i}+j$ surrounding the time $t_{i}$ when an event of type $h$ occurred, for $j \in[-8,8]$, and where $h=I, I_{\text {small }}, I_{\text {big }}, I_{\text {trend }}, I_{\text {wind }}, I_{\exp }$ and $I_{\text {un } \exp }$ (defined in Section 5). Volatility shocks $\Delta V_{i}$ and $\Delta V_{i}(j)$ are measured by changes in $\left|r_{i}\right|$ and $\left|r_{i}(j)\right|$, respectively. The statistics are defined in the notes to Table 6a. A * indicates that the statistic or parameter is significant at the $10 \%$ level or less.

\begin{tabular}{|c|c|c|c|c|c|c|c|c|c|c|}
\hline & $\mathbf{x}_{0 i}$ & $\mathbf{x}_{1 i}$ & $\mathbf{x}_{2 i}$ & $\mathbf{d}_{3 i}$ & $\mathbf{D}_{4 i}$ & $\mathbf{P}_{5 i}$ & $R^{\prime} R_{a}^{2}$ & $\bar{D} D W$ & $B P$ & $N$ \\
\hline \multicolumn{11}{|c|}{$I$} \\
\hline$\Delta S_{i}$ & $5.186^{*}$ & $-0.546^{*}$ & $4.949^{*}$ & $-9.456^{*}$ & -0.0007 & $0.0035^{*}$ & $77.81 \%$ & $0.75^{*}$ & 1.75 & 86 \\
\hline$\Delta S_{i}(j)$ & $5.640^{*}$ & $-0.577^{*}$ & $5.423^{*}$ & -1.203 & $-0.0021^{*}$ & 0.0002 & $39.21 \%$ & $1.24^{*}$ & $228.9^{*}$ & 1,462 \\
\hline \multicolumn{11}{|c|}{$I_{\text {small }}$} \\
\hline$\Delta S_{i}$ & $4.533^{*}$ & $-0.484^{*}$ & $6.838^{*}$ & -6.974 & -0.0011 & $0.0034^{*}$ & $78.24 \%$ & $0.91^{*}$ & 4.43 & 57 \\
\hline$\Delta S_{i}(j)$ & $4.571^{*}$ & $-0.471^{*}$ & $8.931^{*}$ & -1.494 & $-0.0027^{*}$ & 0.0001 & $39.08 \%$ & $1.25^{*}$ & $126.7^{*}$ & 969 \\
\hline \multicolumn{11}{|c|}{$I_{b i g}$} \\
\hline$\Delta S_{i}$ & $6.243^{*}$ & $-0.628^{*}$ & $4.460^{*}$ & $-12.053^{*}$ & $-0.0015^{*}$ & $0.0017^{*}$ & $83.19 \%$ & $0.80^{*}$ & 5.18 & 29 \\
\hline$\Delta S_{i}(j)$ & $6.501^{*}$ & $-0.658^{*}$ & $2.834^{*}$ & -0.275 & $-0.0015^{*}$ & 0.0007 & $53.37 \%$ & $1.25^{*}$ & $313.6^{*}$ & 493 \\
\hline \multicolumn{11}{|c|}{$I_{\text {trend }}$} \\
\hline$\overline{\Delta S_{i}}$ & $6.274^{*}$ & $-0.649^{*}$ & 3.613 & -6.085 & -0.0005 & $0.0034^{*}$ & $77.15 \%$ & $1.07^{*}$ & 6.71 & 22 \\
\hline$\Delta S_{i}(j)$ & $6.062^{*}$ & $-0.622^{*}$ & $4.903^{*}$ & 2.812 & $-0.0018^{*}$ & 0.0003 & $37.04 \%$ & $1.27^{*}$ & $52.7^{*}$ & 374 \\
\hline \multicolumn{11}{|c|}{$I_{\text {wind }}$} \\
\hline$\Delta S_{i}$ & $4.699^{*}$ & $-0.498^{*}$ & $6.399^{*}$ & $-15.080^{*}$ & -0.0009 & $0.0034^{*}$ & $78.49 \%$ & $0.87^{*}$ & 3.54 & 64 \\
\hline$\Delta S_{i}(j)$ & $5.404^{*}$ & $-0.552^{*}$ & $6.511^{*}$ & -2.823 & $-0.0023^{*}$ & 0.0002 & $40.35 \%$ & $1.25^{*}$ & $177.2^{*}$ & 1,088 \\
\hline \multicolumn{11}{|c|}{$I_{\text {exp }}$} \\
\hline$\Delta S_{i}$ & $7.976^{*}$ & $-0.828^{*}$ & 2.827 & 19.623 & $-0.0015^{*}$ & $0.0024^{*}$ & $82.72 \%$ & $1.65^{*}$ & 3.76 & 13 \\
\hline$\Delta S_{i}(j)$ & $8.401^{*}$ & $-0.850^{*}$ & $4.234^{*}$ & 10.251 & $-0.0024^{*}$ & $-0.0003^{*}$ & $47.07 \%$ & $1.36^{*}$ & $38.17^{*}$ & 221 \\
\hline \multicolumn{11}{|c|}{$I_{\text {un exp }}$} \\
\hline$\Delta S_{i}$ & $4.836^{*}$ & $-0.510^{*}$ & $4.655^{*}$ & $-9.007^{*}$ & -0.0006 & $0.0039^{*}$ & $75.36 \%$ & $0.85^{*}$ & 1.04 & 73 \\
\hline$\Delta S_{i}(j)$ & $5.228^{*}$ & $-0.538^{*}$ & $5.575^{*}$ & -1.549 & $-0.0020^{*}$ & 0.0004 & $38.42 \%$ & $1.19^{*}$ & $196.1^{*}$ & 1,241 \\
\hline
\end{tabular}




\section{Figure 1. Number of intraday SNB transactions on CHFUSD}

This figure displays the total number of interventions and customer transactions in the sample over fifteen-minute intervals between 5:00 a.m. and 4:00 p.m. GMT. The local Standard (Summer) Time zones in Zurich, London and New York are GMT+0100 (GMT+0200), GMT (GMT+0100) and GMT-0500 (GMT-0400), respectively.

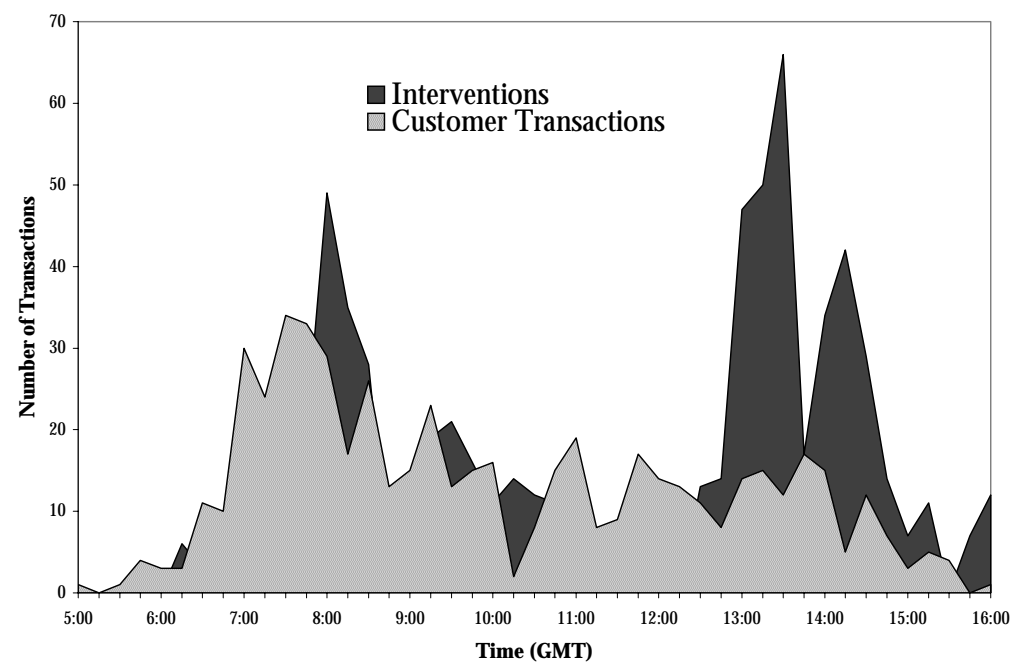

Figure 2. Activity analysis over the length of the sample period

This figure displays the mean daily number of posted indicative quotes, $\bar{k} f_{t}$, over each of the years $k$ for which observations are available in our sample, for $k=1986, \ldots ., 1998$. The light-gray $95 \%$ confidence band centered around that mean is computed using the sample variance estimated over the corresponding one-year interval.






\section{Figure 3. Weekday periodicity in the CHFUSD market}

These figures plot mean values (dark lines) for the daily cumulated return (a), $r_{t}$, daily proxies for exchange rate volatility $\left|r_{t}\right|$ (b) and $r_{t}^{2}$ (c), the absolute spread in units of basis points $S_{t}$ (d), the logarithmic spread $s_{t}$ (e), and the number of posted quotes $f_{t}$ (f), computed over different days of the week, from Monday to Friday. The corresponding 95\% confidence intervals are displayed in light gray. There are 670 Mondays, 669 Tuesdays, 673 Wednesdays, 671 Thursdays, and 669 Fridays in the sample of 3,352 trading days from 1986 to 1998.

a) Return $r_{t}$

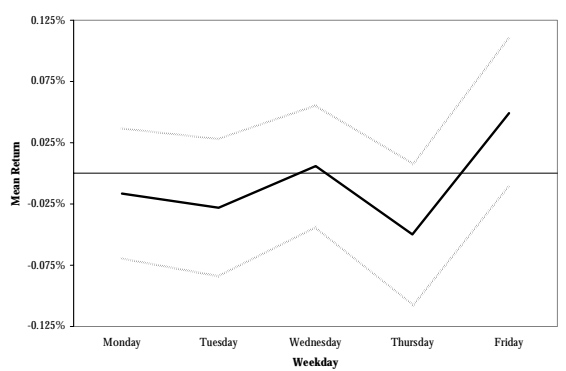

c) Square Return $r_{t}^{2}$

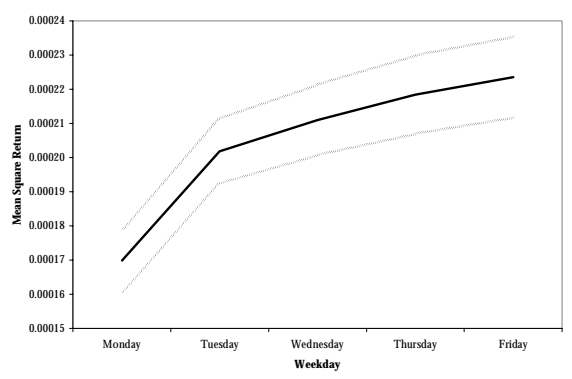

e) Logspread $s_{t}$

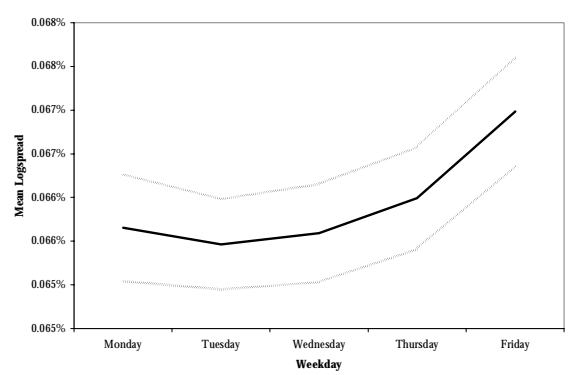

b) Absolute Return $\left|r_{t}\right|$

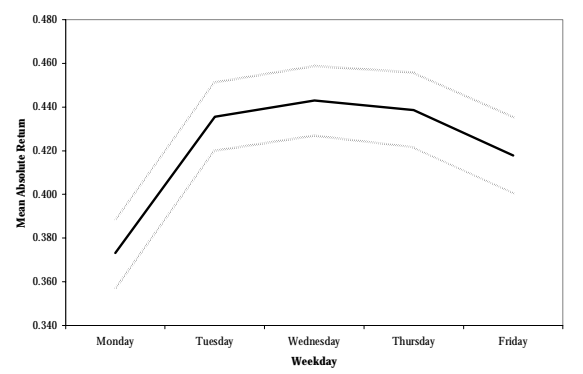

d) Spread $S_{t}$

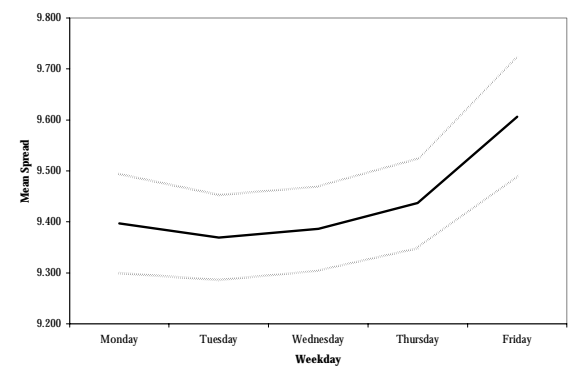

f) Frequency $f_{t}$

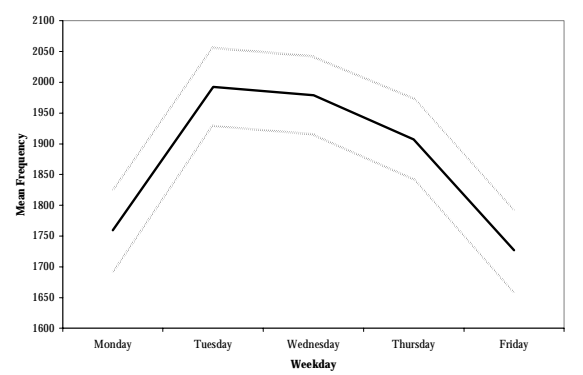


Figure 4. Cumulated impact of interventions and customer transactions

These figures plot (on the left axis) cumulated sums $b_{\text {of estimated dummy coefficients }}$ 8, i.e., of GMM estimates of the following regression specified in Section 3 (Eq. (3)), for each of the variables of interest $X_{t}$, from $r_{t}$ to $f_{t}$, defined in the notes to Table 3 , and for each of the event types $h$, for $h=I, I \gtrless 0, C, C \gtrless 0$, or $I \& C$ :

$$
X_{t}=\alpha+{ }_{l=1}^{\mathrm{P}} \gamma_{l} X_{t-l}+{ }_{j=-8}^{\mathrm{PB}} \delta_{j} I_{t}(j, h)+{ }_{i=1}^{\mathrm{P}} \psi_{i} D_{t}(i)+{ }_{k=1986}^{1997} \vartheta_{k} Y_{t}(k)+\varepsilon_{t}
$$

If, for example, $w>0(w<0)$, then $\oint_{-w}^{h}={ }_{j=w}^{\mathrm{PB}} \boldsymbol{B}_{j}$ is the estimated cumulated impact of actions $h$ on $X$ up to $|w|$ days before (after) they occurred. A ^ indicates that we replaced $I_{t}(j, h)$ in Eq. (3) with the signed event dummy $I_{t}^{*}(j, h)$. Newey-West standard errors for the parameters' estimates are available from the author on request.

a) Return $r_{t}$
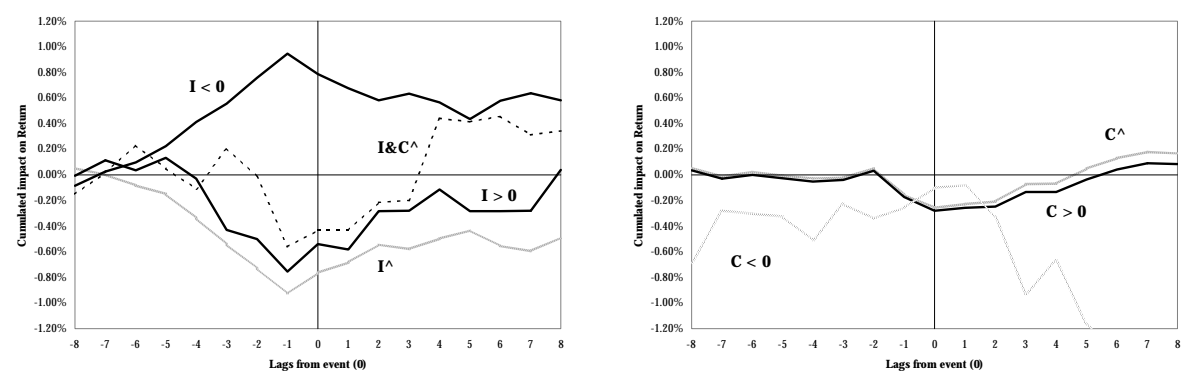

b) Absolute Return $\left|r_{t}\right|$
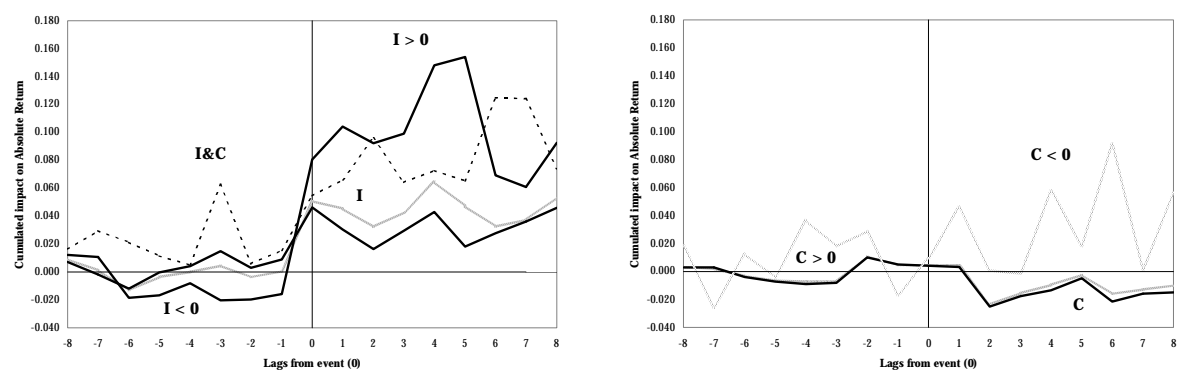

c) Square Return $r_{t}^{2}$
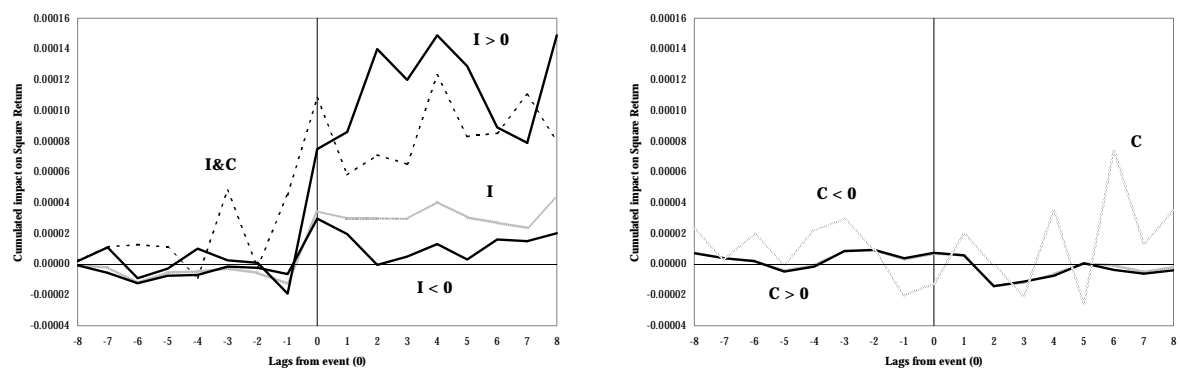
Figure 4 (Continued).

d) Spread $S_{t}$
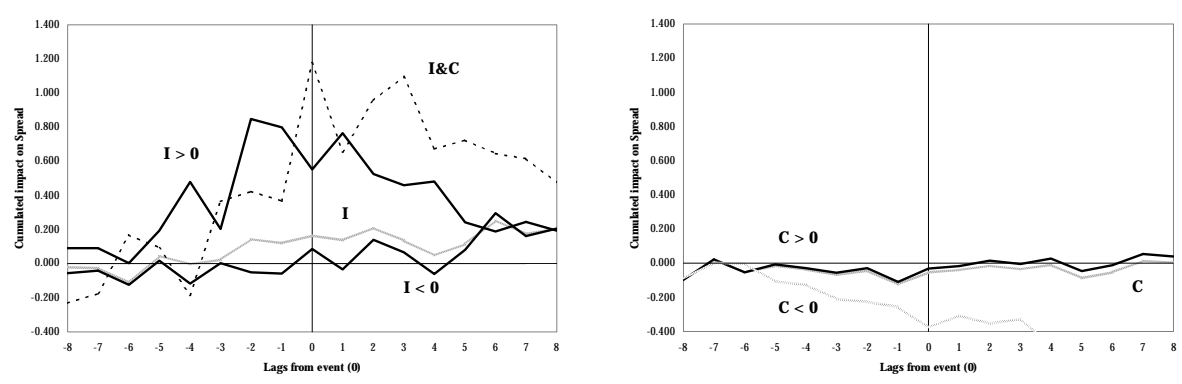

e) Logspread $s_{t}$
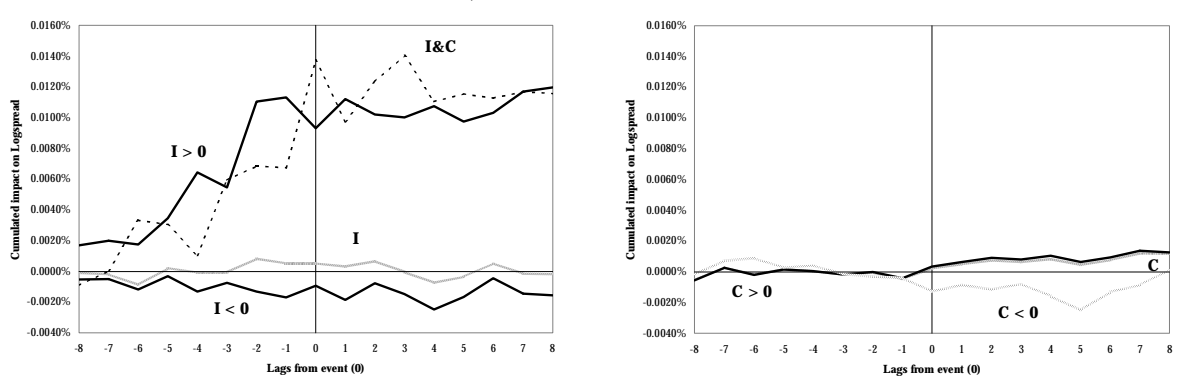

f) Duration $d_{t}$
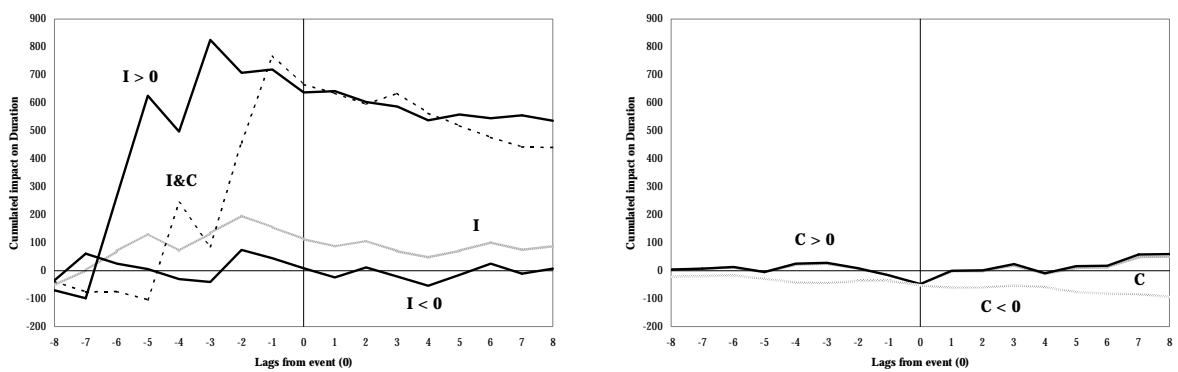

g) Frequency $f_{t}$
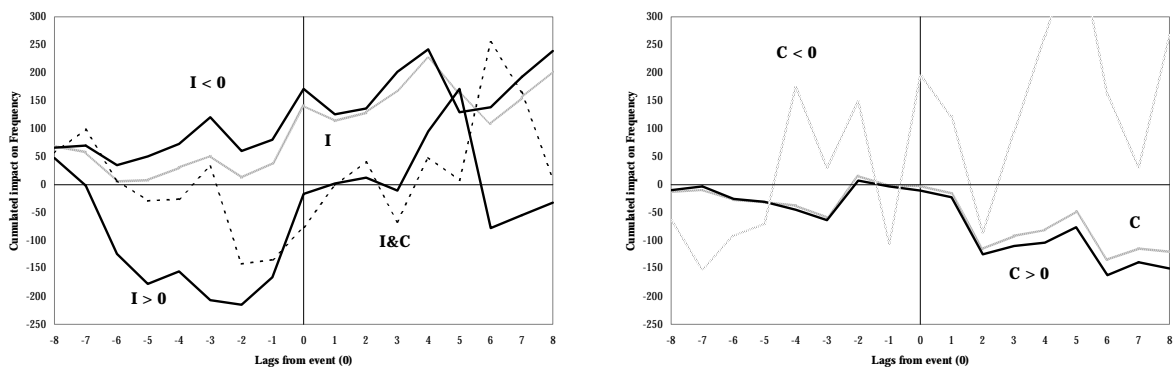
Figure 5. Average spread shock measures $\Delta S_{i}(j)$ over the event interval

This figure displays the average shock in the absolute spread, $\Delta S_{i}(j)=S_{i}(j)-\bar{S}_{i}^{b}$, defined in Section 5. The averages $\overline{\Delta S_{i}(j)}$ are computed over the days in the sample where the corresponding event type $h$ was observed. The benchmarks $\bar{S}_{i}^{b}$ for event $h$ are computed over the first 20 days in the sample preceding the third to last day of the event interval that do not contain any past event of the same type. Hence, benchmarks may be different depending on the event type under study. We analyze subsamples of all interventions $(h=I)$, of all official USD purchases $(h=I>0)$ and sales $(h=I<0)$, all customer transactions $(h=C)$, and of all days when transactions of both type $h=I$ and type $h=C$ (all of which were CHF sales) took place $(h=I \& C)$.

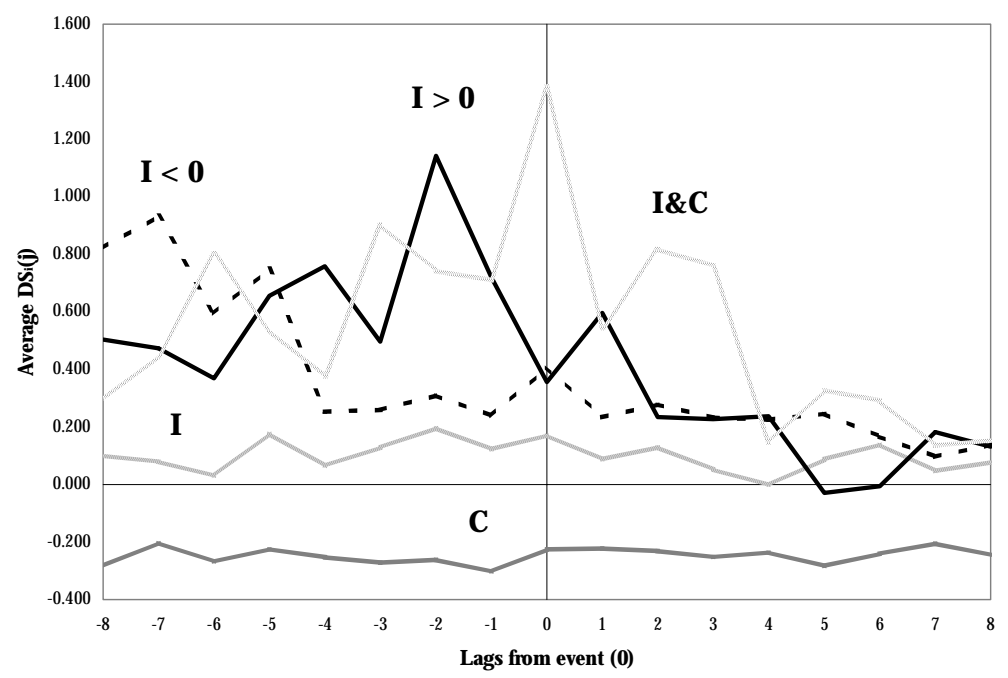




\section{Figure 6. Additional cumulated impact of interventions}

These figures plot (on the left axis) cumulated sums $b_{\text {of estimated dummy coefficients }}$ 8 , i.e., of GMM estimates of the following regression specified in Section 3 (Eq. (3)), for four selected variables of interest $X_{t}$, i.e., $r_{t}, r_{t}^{2}, S_{t}$, and $d_{t}$, defined in the notes to Table 3 , and for each of the following action types $h=I$ (punctuated line), $I_{\text {small }}$ and $I_{b i g}$ for size (dotted lines), $I_{\text {trend }}$ and $I_{\text {wind }}$ for direction (dark lines), and $I_{\exp }$, and $I_{\text {un exp for }}$ market expectations (gray lines), defined in Sections 3 and 5:



If for example $h=I$ and $w>0(w<0)$, then $\boldsymbol{b}_{-w}^{h}={ }_{j=w}^{\mathrm{PB}} \boldsymbol{\otimes}_{j}$ is an estimate of the cumulated impact of official SNB interventions on $X$ up to $|w|$ days before (after) these interventions occur. A ${ }^{\wedge}$ indicates that we replaced $I_{t}(j, h)$ in Eq. (3) with the signed event dummy $I_{t}^{*}(j, h)$. Newey-West standard errors for the parameters' estimates are available from the author on request.

a) Return $r_{t}$



c) Spread $S_{t}$

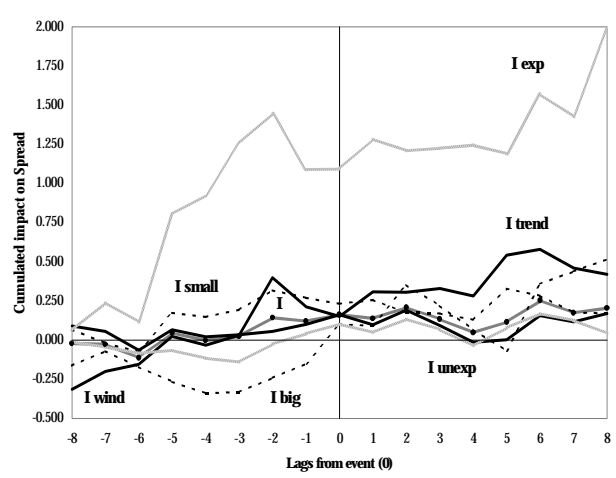

b) Square Return $r_{t}^{2}$

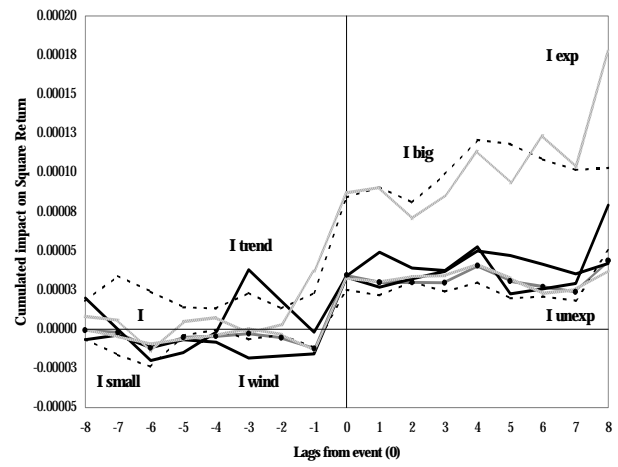

d) Duration $d_{t}$

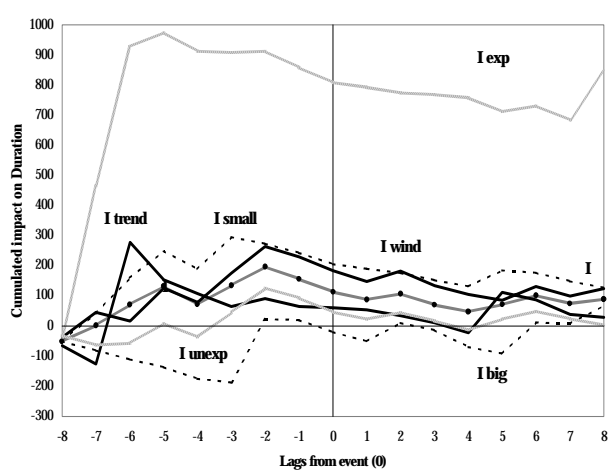

